Epistemologías Críticas Feministas $\mid 1$

\title{
REFLEXIONES SOBRE LA EDUCACIÓN DESDE LAS EPISTEMOLOGÍAS CRÍTICAS FEMINISTAS
}

Trabajo de grado|

\author{
Yamid Gelves Cáceres \\ Universidad Santo Tomas \\ Facultad de Filosofía y letras \\ Maestría en Filosofía Latinoamericana
}

Bogotá, Diciembre 20 de 2016 


\section{Epistemologías Críticas Feministas}

\section{Resumen}

La presente investigación incorpora la perspectiva de la «equidad de género» y de las ciencias al margen de los sesgos androcéntricos en la Educación Primaria y Secundaria que proponen las epistemologías críticas feministas como alternativa frente los modelos educativos tradicionales de las ciencias. Para realizar esta tarea, se va a realizar -de manera general- un recorrido por los planteamientos que autores como Harding, Thuillier, Morin, entre otros, han realizado sobre las epistemologías «tradicionales», las Epistemologías Críticas y las epistemologías críticas feministas.

Palabras Claves: epistemología, epistemologías críticas, feminismos, androcentrismo, educación. 


\section{Epistemologías Críticas Feministas}

\section{Agradecimientos}

A todos los docentes que han contribuido con sus conocimientos a generar una perspectiva crítica frente a la filosofía, a la maestra Claudia Giraldo por el acompañamiento y dedicación para que este trabajo hoy fuese realidad, a la comprensión de mi hija Laura Alejandra Gelves porque tuvo que ceder sus espacios para que yo asistiera a las clases y dedicara tiempo de estudio en casa, a todos ellos gracias porque me brindaron la oportunidad de crecer un poco más a nivel espiritual y cognitivo. 
\begin{tabular}{l|l} 
& 4
\end{tabular}

Tabla de Contenido

INTRODUCCIÓN

CAPÍTULO I. CONTEXTUALIZACIÓN DE LAS EPISTEMOLOGÍAS CRÍTICAS

FEMINISTAS.......................................................................................................................99

La historia internalista de la ciencia y la historia de la ciencia como producto cultural ..............10

Crítica y autocrítica de las ciencias: La epistemología crítica y las epistemologías feministas.....20

Reflexiones feministas sobre la epistemología ................................................................24

Las epistemologías críticas feministas .................................................................................27

Críticas de Sandra Harding a las críticas feministas ...........................................................33

CAPITULO II. ALGUNAS PROPUESTAS DE LAS EPISTEMOLOGÍAS CRÍTICAS

FEMINISTAS A LAS LIMITACIONES DE LA CIENCIA TRADICIONAL ................... 41

Las limitaciones de la ciencia según las Epistemologías Críticas Feministas (ECF)...................41

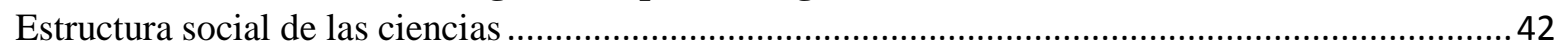

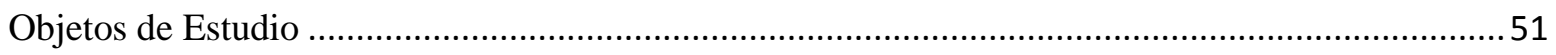

Conceptos, marcos teóricos y problemas científicos..................................................................5

Propuestas de las epistemologías críticas feministas para contrarrestar las limitaciones de la

filosofía de la ciencia y de la ciencia no crítica..................................................................58

Acceso y participación a la educación y al trabajo científico .........................................................5 58

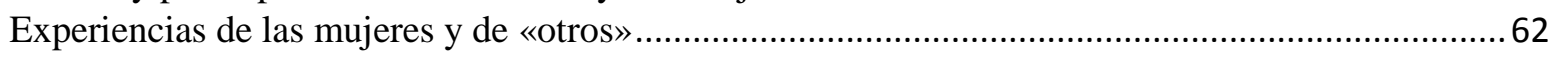

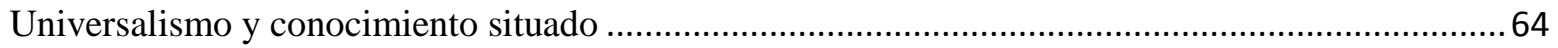

CAPITULO III. EDUCACION PARA LA EQUIDAD DE GÉNERO DESDE LAS PERSPECTIVAS EPISTEMOLÓGICAS CRÍTICAS FEMINISTAS ............................... 70

El docente $\mathbf{y}$ «los estereotipos de género» ........................................................................72

Los currículos y la perspectiva de género..................................................................................77

El estudiante y la perspectiva de género...............................................................................84 


\section{Epistemologías Críticas Feministas}

\section{INTRODUCCIÓN}

En este ejercicio de investigación, exploraremos los aportes que las epistemologías críticas pueden hacer a la educación que se imparte en los niveles de Primaria y Secundaria, buscando una educación para la equidad de género desde la crítica social y epistémica. El principal referente para esta investigación son la filósofa Sandra Harding, de quien se retomará la perspectiva epistemológica crítica feminista y se extraerán los principales argumentos que van a enmarcar en el transcurso del texto; sin embargo, en el primer capítulo, para situar las epistemologías críticas feministas, fue necesario recurrir al Francés Pierre Thuillier y la concepción de ciencia y sociedad que desarrolla en sus investigaciones epistemológicas.

La estructura del texto está constituida por tres capítulos. El primero es titulado: Contextualización de las epistemologías críticas feministas, allí se presentan algunas definiciones clásicas que se han realizado acerca de la epistemología, también se extrae el planteamiento de Thuillier, que apoya y fundamenta la importancia de retornar a la historia y a la sociedad para comprender los procesos epistemológicos y para mejorar las elaboraciones epistémicas hasta el momento realizadas. Se introducen también desde Harding, los principales argumentos que han contribuido a la elaboración de las epistemologías críticas feministas y la respectiva fricción que esta perspectiva relaciona con las epistemologías tradicionales.

En el segundo capítulo titulado Algunas propuestas de las epistemologías críticas feministas ${ }^{1}$ a las limitaciones de la ciencia tradicional, se contextualizan las limitaciones de la ciencia que las epistemologías han encontrado y las propuestas que las epistemologías críticas feministas plantean en torno a estas limitaciones. Teniendo en cuenta el complicado proceso que las mujeres han tenido que afrontar para ser incorporadas como sujetos de estudio, ser tituladas y por último acceder al mundo laboral; un recorrido que por las luchas libradas en el siglo XXI encuentra mayores oportunidades para alcanzar la equidad en siglos anteriores. También se presentan los planteamientos que Harding y otras pensadoras realizan para superar el sesgo androcéntrico de las ciencias y así formular un modelo de las ciencias más equitativo y transparente en relación con la creación y reproducción del conocimiento científico.

\footnotetext{
${ }^{1}$ De aquí en adelante se usará la abreviatura ECF para reemplazar el concepto de Epistemologías Críticas Feministas
} 


\section{Epistemologías Críticas Feministas $\mid 6$}

En el tercer y último capítulo titulado Educación para la equidad de género desde las perspectivas epistemológicas críticas feministas, se plantea como alternativa a los procesos educativos tradicionales que siguen reproduciendo el sesgo androcéntrico de las ciencias y la inequidad social, un modelo educativo que involucre a toda la comunidad educativa en el proceso de minimizar los estereotipos de género que giran en torno al simbolismo de género, la estructura de género y el género individual y que fomente procesos educativos ecuánimes. Esta perspectiva de educación tiene como antecedentes, las epistemologías críticas y como proyecto, la formulación de una educación para la equidad de género.

La conclusión final gira en torno a que sí es posible incorporar en la Educación Primaria y Secundaria las propuesta de las ECF, siempre y cuando se ajusten algunos principios que cambien la perspectiva tradicional del proceso enseñanza-aprendizaje ${ }^{2}$, para promover un modelo educativo basado en la equidad y el acceso al conocimiento libre del sesgo androcéntrico; estimular la participación y el ejercicio de las mujeres en los diferentes campos disciplinares y laborales; y, promover relaciones interpersonales equitativas en las que la dignidad humana sea el requisito rector.

Los métodos utilizados para esta investigación son la revisión bibliográfica y la deducción. A través de la revisión bibliográfica se realizaron actividades como: localización, búsqueda, identificación, selección, análisis crítico y descripción sobre la inequidad del género en el quehacer científico así como los sesgos androcéntricos que han producido y reproducido a través de las ciencias los estereotipos de género. A través de la deducción, se infirió los dos primeros capítulos los postulados que desde las ECF, permitían formular e incorporar estrategias para la implementación de una educación para la equidad de género.

Los principios rectores que se han estructurado en la consecución de una educación para la equidad son: 1) Cambiar la perspectiva frente al género que los docentes y las docentes heredaron de sus familias, de la sociedad y de las universidades, con el fin de promover procesos

\footnotetext{
${ }^{2}$ Entenderemos en el transcurso del texto los conceptos Enseñanza-Aprendizaje de la siguiente manera: Enseñar es favorecer la construcción de conocimientos de tipo informativo y formativo a los alumnos. Aprender es adquirir conocimientos, no sólo de tipo informativo sino también formativo.
} 


\section{Epistemologías Críticas Feministas}

de enseñanza-aprendizaje equitativos libres del sesgo androcéntrico, 2) la articulación de algunos planteamientos de las ECF en el currículo, en aras de garantizar el reconocimiento de las mujeres como sujetos de conocimiento 3) motivar al estudiante para que opte siempre por la reflexión crítica, por el reconocimiento de la practicidad del quehacer científico en la problematización y solución de las necesidades y oportunidades que se presentan en el contexto en el que se encuentra.

La comprensión de algunos de los postulados que se han hecho explícitos en esta investigación han motivado reflexiones en torno al quehacer docente y a la forma en que las enseñanzas y actitudes de parte de los docentes y las docentes, consciente e inconscientemente, ejercen algún tipo de impacto negativo o positivo en el educando y en la sociedad. Comprender que la falta de información y el desconocimiento reproducen estereotipos que determinan el proceder individual y colectivo de hombres y mujeres lleva a continuar en la búsqueda del conocimiento, en pro de la dignidad humana, independientemente de la clase social, del género, de la etnia o de cualquier configuración social.

Después de profundizar en los pocos planteamientos que se han explicitado sobre las epistemologías críticas feministas, queda el sinsabor y la incertidumbre de continuar postergando en los estudiantes los modelos epistémicos y las estructuras sociales, que tienen como finalidad, para su sostenimiento, someter al otro que lo cuestiona, lo confronta y le exige replantear algunos planteamientos para continuar dinamizando el saber científico.

La incertidumbre que hemos experimentado al realizar esta investigación, también motiva a continuar reflexionando de manera crítica y autocrítica sobre la forma en que se produce, estructura y reproduce el saber científico. Ahora, esta reflexión en nosotros tiene algunas herramientas que permiten vislumbrar con más claridad pero siempre amasando la duda y la desconfianza frente a categorías tales como la universalidad, la objetividad, la neutralidad, la univocidad, y la existencia de un sesgo androcéntrico que nos ha limitado a conocer tan solo una perspectiva (la masculina), sobre el conocimiento del mundo. 


\section{Epistemologías Críticas Feministas}

Como parte del grupo de pensadores sobre la filosofía latinoamericana, y siendo conscientes del calificativo despectivo (pensadores subalternos e inauténticos) que han hecho algunos filósofos europeos sobre las reflexiones filosóficas que se han elaborado en América Latina, encontramos argumentos para rebatir la concepción utópica de normalizar y hegemonizar un modelo de pensamiento como el único posible. Concebimos la problematización de la realidad históricoespacial del individuo como el laboratorio más especializado para hacer ciencia y para replantear los postulados cuantas veces sea posible en aras de aproximarnos un poco más a la verdad.

La construcción epistemológica de esta investigación también se presenta como un ejercicio de constante autocrítica que debe continuar estimulando las confrontaciones teóricas, metodológicas e ideológicas que se instauran como paradigmas. De igual forma, muestra la necesidad de continuar cultivando un modelo de las ciencias flexible y humano, en el que la responsabilidad del investigador así como la articulación de sus prácticas científicas, contribuyan a mejorar la calidad de vida, a preservar las especies que cohabitan en el planeta, con el propósito de incentivar el sostenimiento natural de las especies. 


\section{CAPÍTULO I. CONTEXTUALIZACIÓN DE LAS EPISTEMOLOGÍAS CRÍTICAS FEMINISTAS}

El problema de esta investigación gira en torno a las condiciones en que se educa a los jóvenes y las jóvenes en la actualidad, desde la perspectiva de las epistemologías críticas feministas. El campo de reflexión enmarca algunos planteamientos -no todos- de las epistemologías tradicionales, las epistemologías críticas, las ECF y el análisis de algunas propuestas pedagógicas para la equidad de género. Así será posible identificar, cómo la educación asume los modelos de enseñanza tradicional y transmite el conocimiento científico. Cuál es la relación que existe entre la educación, el modelo de ciencia que se transmite, la reproducción de relaciones sociales inequitativas y el sesgo androcéntrico.

En este primer capítulo, el objetivo es ubicar las epistemologías críticas feministas en el amplio campo de la epistemología. Aclarar qué se entiende por ECF y mostrar que no se trata de un enfrentamiento entre unas epistemologías mal llamadas tradicionales y unas epistemologías feministas, sino de un largo y ya consolidado debate en el interior de la filosofía de la ciencia que se ha centrado en dilucidar la relación entre ciencia y cultura. Estas reflexiones han sido múltiples y se identifican con diferentes debates, algunos ya clásicos, como el de comprensiónexplicación, saber-poder, sociología de la ciencia-filosofía de la ciencia, entre otros. Se busca resaltar aquellos aspectos en el interior de la epistemología que se han problematizado, especialmente desde la llamada epistemología crítica y de las ECF.

Para desarrollar este apartado se tienen en cuenta los planteamientos epistemológicos de algunos filósofos de la ciencia del siglo XX. Como punto de referencia se retoman a Pierre Thuillier y Sandra Harding. Favorecer esta reflexión, permite identificar en esta investigación, las alternativas existentes, las debilidades y las oportunidades frente a las formulaciones tradicionales de la epistemología que se han divulgado y validado en las instituciones educativas a través de los procesos de enseñanza-aprendizaje. 


\section{La historia internalista de la ciencia y la historia de la ciencia como producto cultural}

Según Thuillier ${ }^{3}$, se han identificado formas diferentes de abordar y definir «la epistemología». Esta variedad conceptual ha surgido a través del tiempo, dependiendo del momento histórico y contextual en el que se han querido definir las epistemologías. Por la forma en que se ha estudiado y por los innumerables tratados que han surgido sobre la filosofía de la ciencia, se puede afirmar que la ciencia no ha sido un objeto de estudio estático en la historia; todo lo contrario, se puede demostrar la mutabilidad existente cuando se dan los cambios entre un paradigma y otro, entre un pensador y otro, e incluso entre una disciplina y otra. Pese a esta variabilidad se pueden identificar, según los estudios realizados por Thuillier —entre otros filósofos de la ciencia- dos grandes formas en que se ha desarrollado la filosofía de la ciencia o mejor, un debate en la constitución de la misma: el debate internalismo-externalismo.

Harding $^{4}$ entiende el programa internalista y el programa externalista como dos enfoques que han querido explicar la aparición de la ciencia moderna. Según la filósofa

El programa internalista asumió que la reconstrucción racional de la evolución de la ciencia proporcionaría de forma inmediata una historia de la ciencia relevante completa. [...]. El programa internalista intentó elaborar una reconstrucción racional de la evolución de la ciencia con respecto a la cual no aportara ninguna prueba refutadora $(1996$, p. 182183).

\footnotetext{
${ }^{3}$ Pierre Thuillier (1932 - 29 de septiembre de 1998), fue un filósofo francés. Enseñó epistemología e historia de la ciencia en la Universidad de París VII Denis Diderot. Director y redactor de la revista La Recherche hasta 1994, conocida por las explicaciones que daba al público sobre los avances de la ciencia. Publicó numerosos libros y artículos sobre la relación entre ciencia y sociedad. También fue un estudioso de la historia del pensamiento evolucionista.

${ }^{4}$ Sandra Harding Sandra G. Harding (1935) es filósofa y feminista. Obtuvo su doctorado por la Universidad de Nueva York en 1973. Sus trabajos se enmarcan dentro de la Filosofía de la Ciencia, la Epistemología Feminista, la Teoría postcolonial y la metodología en investigación. Actualmente, Harding es profesora en la Universidad de California, Los Ángeles. Harding fue la primera directora del 'Centro de estudio de la mujer' de la Universidad de California, Los Ángeles (1996-2000), y codirectora de la prestigiosa revista feminista publicada por University of Chicago Press, Signs: Journal of Women in Culture and Society (2000-2005). También trabajó como profesora en la Universidad de Delaware, y ha sido profesora invitada en la Universidad de Ámsterdam, la Universidad de Costa Rica y la Escuela politécnica federal de Zúrich, Suiza.
} 
Cuando los herederos del positivismo lógico, intentaron elaborar las reglas de la investigación social, que deberían guiar sus propias ideas sobre la ciencia moderna, se encontraron con la disputa entre naturalistas e intencionalistas, inclinándose por la postura naturalista. Esta insiste en que solo hay una lógica explicativa, tanto para los fenómenos sociales como para los naturales que es la llevada a cabo en las ciencias naturales. En consecuencia, tendríamos que considerar que el programa interno en la historia y la filosofía de la ciencia, que acepta el desarrollo de las ciencias como un fenómeno social; defiende un enfoque intencionalista exclusivamente para explicar el desarrollo de la ciencia, cualquier otro fenómeno social distinto al desarrollo de la ciencia, requiere una explicación naturalista, siendo así el internalismo un naturalismo incompleto. «El desarrollo de la ciencia solo ha de entenderse mediante los relatos que los científicos y la cultura científica hacen de sí mismos» (Harding, 1996, p. 184).

Los externalistas acuden a dos argumentos diferentes para justificar sus proyectos. En primer lugar comparten el argumento de los internalistas de que el problema de la ciencia pura, libre de artificios humanos, ha de entenderse a través de la conciencia de sus creadores, y en segundo lugar, consideran que «las estructuras cognitivas de la ciencia se justifican como emergentes históricos que acompañan la progresividad potencial de las tecnologías que hagan posible estas estructuras cognitivas» (Harding, 1996, p. 185).

El punto de encuentro entre los dos programas, se encuentra en el acceso a la historia y la influencia que tienen de la cultura. El programa interno no sólo trata de reconstruir la evolución de la ciencia desde el punto de vista lógico sino también de explicarlo históricamente. «Asume una historia de las estructuras intelectuales independiente; el desarrollo de las formas de conocimiento es una variable independiente de la evolución cultural» (Harding, 1996, p. 182). El programa externalista encuentra en las estructuras sociales y en el medio ambiente de la ciencia, constitutivos indisolubles de esta.

Siguiendo el objetivo de este apartado, abordaremos especialmente la perspectiva externalista en su versión de «la ciencia como producto cultural» para identificar las condiciones de posibilidad de las epistemologías críticas, de las epistemologías críticas feministas y algunos de sus postulados. Sin embargo hay que mencionar que aunque cada perspectiva tiene sus propias 
preocupaciones y abordajes, existe el llamado internalismo flexible que coincide con los externalistas en que la filosofía de la ciencia no puede obviar el carácter social e histórico de la ciencia.

Por ejemplo, Díez y Moulines (1999) en el texto Fundamentos de filosofía de la ciencia, habla sobre el surgimiento y el desarrollo de la filosofía de la ciencia, dicen:

Por lo que a la revuelta historicista se refiere, aunque en las décadas anteriores hay algunos precursores de la crítica historicista a la filosofía clásica de corte "positivista" (principalmente Ludwik Fleck y Michael Polányi), la corriente historicista se hace fuerte como nueva alternativa a partir de los años sesenta, principalmente con los trabajos de Thomas S. Kuhn, Paul K. Feyerabend e Imre Lakatos entre los que destaca de modo particularmente La estructura de las revoluciones científicas de Kuhn, aparecido en 1962 (...) El principal y más explícito reproche que estos autores hacen a la filosofía clásica de la ciencia estriba en que ésta no se tomara la historia de la ciencia en serio y que, en consecuencia, presentara una imagen muy pobre, totalmente inadecuada, de la dinámica del conocimiento científico (p. 31-32).

La corriente historicista de acuerdo con los autores, muestra una clara oposición frente a la filosofía clásica de la ciencia y una gran vocación de ruptura en lo referente a la relación que debe establecerse entre filosofía e historia de la ciencia. Según ellos, la perspectiva historicista de las ciencias plantea que cualquier análisis de la dimensión diacrónica de las teorías científicas debe partir de que las teorías diacrónicamente consideradas, en tanto que entidades que perduran en el cambio a través del tiempo, consisten en determinadas secuencias de «teorías en sentido sincrónico», así:

La "historia" de una teoría consiste en la sucesión de las diversas "etapas" o versiones por las que pasa. Estas etapas, en tanto que imágenes "congeladas" de la teoría en cierto momento se deben considerar aproximadamente estables o "estáticas". La cinemática de la teoría, su "historia", consiste en la sucesión de diversas versiones estáticas, en la sucesión de “etapas", por las que la teoría pasa (p. 310). 


\section{Epistemologías Críticas Feministas}

Entendemos que los análisis diacrónicos presuponen alguna noción de la estructura sincrónica de las teorías, de las etapas cuya sucesión constituye, como dicen los pensadores, teoría-en-eltiempo. Para Kuhn, y en menor medida de elaboración, a causa de su muerte; para Lakatos, los componentes históricos y sociales en cuanto vinculados de manera in-eliminables a la actividad científica, son inaccesibles al análisis formal.

Todo el proyecto original de desarrollar una lógica de la ciencia, incluida en ella, la reconstrucción de las teorías, está según ellos abocado al fracaso. El análisis de las teorías según esta perspectiva -comentan Díez y Moulines- «ha de ser tal que estas resulten entidades susceptibles de evolución, que puedan sufrir modificaciones extendiéndose en el tiempo sin perder su identidad» (Díez y Moulines, 1999, p. 310). Como vemos la perspectiva internalista flexible no pudo dejar de lado la necesidad de introducir el problema de la historia en la filosofía de la ciencia.

Al respecto Edgar Morin en el texto Ciencia con Conciencia, nos habla sobre la aportación decisiva de la epistemología moderna que la evolución científica es una evolución de la propia visión de las cosas o de lo real, es decir que la ciencia se desarrolla por revoluciones paradigmáticas. Kuhn, comenta Morin, plantea que:

Los paradigmas son algunos principios que asocian y disocian las nociones fundamentales que rigen y controlan todo el discurso teórico. Una pequeñísima modificación de paradigma, como por ejemplo, el paso del paradigma ptolemaico -en el cual el sol gira alrededor de la tierra- al paradigma galileano - que enuncia que la tierra gira alrededor del sol-, lleva consigo, efectivamente consecuencias considerables en la propia visión del mundo y del lugar de la humanidad en el seno del universo (Kuhn, como se citó en Morin, 1982, p. 58).

Morin muestra aquí que, desde la perspectiva de Kuhn, la ciencia posee algunos principios que rigen de manera oculta el conocimiento científico que se encarga de organizar y validar el saber no necesariamente a través de principios lógicos. Los paradigmas -según las interpretaciones de 
Morin sobre Kuhn-son modelos, patrones, reglas o normas compartidos por hombres de ciencia, son en esencia, acuerdos sociales; por esta misma esencia social e histórica que poseen, siempre están incompletos y son susceptibles de cambio.

Conceptos como paradigma, revoluciones paradigmáticas y evolución científica, que utiliza Kuhn, permiten deducir, que incluso autores canónicos no historicistas sino de corriente más internalista de la talla de este pensador y de otros ya mencionados, no pueden negar la dimensión social de la ciencia. El saber científico como lo afirma Popper, progresa por la eliminación de errores, mas no por el aumento de verdades; o como afirma Kuhn, la ciencia se desarrolla por revoluciones paradigmáticas. Es decir, a medida que han venido avanzando las investigaciones y descubrimientos, el ser humano ha podido esclarecer y precisar las teorías, hipótesis, leyes, y mitos que en algún momento se han consensuado como verdad, pero que han sido replanteados en cuanto a lo teórico y práctico, generando una perspectiva diferente a la que se tenía. son indispensables «las crisis»o «las anomalías» paradigmáticas para reescribir un paradigma nuevo.

Esta perspectiva también afirma que la dinamicidad de las investigaciones y la movilidad que tiene el saber científico han generado la necesidad de crear métodos diferentes. Se pueden señalar métodos definitorios, métodos clasificatorios, métodos estadísticos, métodos hipotéticodeductivos, procedimientos de medición y muchos otros, de modo que hablar de "método científico" implica referirse a un vasto conjunto de tácticas empleadas para constituir el conocimiento. Este conjunto de tácticas se van modificando con el tiempo, por ello, el conocimiento de la historia de la ciencia es de gran utilidad para lograr mejoras en el "método científico".

Retomando a Thuillier y su perspectiva externalista, en el prefacio del texto El Saber Ventrilocuo (1990), señala el trasfondo filosófico, religioso, político y social de la ciencia, afirmando que:

"La ciencia" es una construcción humana, una institución progresivamente elaborada, históricamente condicionada e inseparable de las demás instituciones o actividades humanas. En grados diversos y bajo modalidades no menos diversas, las actividades llamadas "científicas" son tributarias de una inagotable serie de factores filosóficos, 
religiosos, políticos, económicos, estéticos, etcétera. Estudiar "la ciencia" como una realidad cultural es tratar de aprehender su complejidad. Y, en particular, descubrir los riesgos que corre, las pasiones que la hacen vivir, los intereses varios que en ella se expresan bajo formas más o menos sublimadas (p. 7).

La epistemología o la filosofía de la ciencia, según Thuillier, no impone dogmas a los científicos sino que estudia la génesis y la estructura de los conocimientos científicos, a esto añade que los epistemólogos estudian tanto la génesis como la estructura de la ciencia, desde un punto de vista lógico, histórico y sociológico. Además dice que la epistemología no es un sistema dogmático conformado por leyes inmutables e impuestas; sino que más bien, es ese trasegar por el conocimiento científico que se mueve en los imaginarios de la época las reflexiones sobre el mismo y el quebranto o «crisis» de las normas que sustentan un paradigma en particular propio de una comunidad científica. Por tal razón, este autor afirma que es difícil llegar a una definición unívoca de epistemología, de hecho en algunos contextos, usa el concepto de epistemología como sinónimo de filosofía de la ciencia. Thuillier plantea:

El simple hecho de que dudamos entre dos denominaciones es revelador: ora decimos epistemología (que es una palabra con aspecto serio, «científico»), ora hablamos de filosofía de las ciencias (que parece más «literario» y despierta la desconfianza) el concepto de epistemología es de hecho empleado de diversas maneras: según el país y para lo que se use, sirve para designar una teoría general del conocimiento (de naturaleza filosófica), o bien para estudio más pormenorizados sobre la génesis y la estructura de las ciencias (Thuillier como se citó en Mardones, 2001, p. 63).

Es tipo de ambigüedad nos permite decir, que no existe certeza objetiva que universalice alguna definición. No queda más remedio que aceptar que el conocimiento sobre el conocimiento científico también es contingente, pero no por eso inválido. Se trata de campos que escudriñan cómo el ser humano ha comprendido su entorno por la vía de métodos experimentales o hermenéuticos en el deseo o necesidad de explicar y comprender los fenómenos.

Los planteamientos de Thuillier ubican la epistemología en un trasegar histórico, sujeto a los 
acontecimientos que emergen en la realidad humana, que mueve a los filósofos y a los científicos a reflexionar sobre aquello que afecta el quehacer científico en un tiempo y espacio determinado. Relacionar la epistemología con los acontecimientos de la historia, es involucrar la ciencia con las instituciones de la sociedad, con los saberes ideológicos de la época, con el impacto y transformación cultural causados por un conocimiento objetivo que a veces se ve a sí mismo como abstraído de la realidad. Blanco (1994) afirma que esta necesidad de enfatizar en la relación entre ciencia y sociedad es propia del siglo XX:

Hasta finales del siglo XIX la separación entre ciencia y sociedad no era tan evidente como en la actualidad. Al contrario, existía entre ambas esferas una comunicación y apoyo mutuo que hacía difícil establecer una demarcación tan acentuada como la existente hoy en día. Los intereses públicos influían poderosamente sobre la dirección del trabajo científico y la definición de lo que se consideraba como conocimiento científico. La situación cambió de forma sustancial durante el siglo pasado. Progresivamente, la comunidad científica erigió fronteras más precisas, elevando el grado de compromiso profesional hasta excluir a los amateurs. El campo quedó así dividido entre especialistas (la ciencia) y legos (la sociedad) (p.35).

Edgar Morin pretende disminuir la brecha que ha separado lo científico de lo social. Este pensador afirma que la cientificidad comprende un universo de teorías, de ideas, de paradigmas que se hallan inscritas en la cultura, en la historia y en la sociedad. Según este pensador, no existe la ciencia vista como la pura transparencia de las leyes de la naturaleza. Para encontrar y probar las leyes de la naturaleza, no es necesario que el conocimiento, los conceptos y las teorías que dan forma a estas leyes, se vuelvan bruscamente intemporales y universales. Para Morin (1982):

Los conceptos que parecen más evidentes hoy, como el de energía, han sido producidos por un siglo de reflexiones e investigaciones a partir de las nociones de fuerza y trabajo, trasplantadas a su vez de la experiencia social y humana. La energía, que se convirtió en el concepto clave de la ciencia física del siglo XIX, es inseparable de una historia social (p. 59). 
La construcción del saber no es indiferente a los descubrimientos que la humanidad ha realizado en su diario vivir, es más, cada situación específica de los hombres y de las mujeres ha contribuido de manera contundente en la reelaboración del saber científico. Debemos reconocer -dice Morin- que:

(...) nos hallamos en una cultura de la que la ciencia es parte integrante. Una cultura comporta una visión del mundo, un modo «de recortar y percibir» lo real. El modo de «recortar y percibir» de una ciencia en una época dada no es eterno. Así por ejemplo, durante dos siglos, el conocimiento ha intentado reducir lo complejo a lo simple, los objetos compuestos a las unidades fundamentales por las que estaban constituidos y reconocer las leyes que regían estos objetos (p. 60).

Adicionalmente advierte que esas interpretaciones siempre han sido el producto de un consenso entre sujetos que se han aproximado a elementos comunes de una realidad posible y no a leyes que todos han percibido de manera univoca e inmutable.

En otro apartado «la reintroducción del sujeto en el conocimiento científico» del mismo texto, Morin hace énfasis en la importancia que tiene el sujeto para reinterpretar además del objeto físico, los caracteres culturales de los conceptos y teorías físicas así como el papel que juega el investigador en la sociedad. «Semejante esfuerzo supone la introducción de la reflexividad consciente, es decir, la reintroducción del sujeto en el conocimiento científico» (p. 63).

Así, la necesidad de introducir una ciencia de la ciencia como lo expone Edgar Morin en el transcurso del texto Ciencia con Conciencia, permite superar los condicionamientos que se han venido planteando para monopolizar la ciencia. La creación de unos lineamientos podría abrir la posibilidad para reconocer las disciplinas emergentes y para validar con el carácter de ciencia las investigaciones que realizan aquellos investigadores que no hacen parte del grupo selecto de científicos. Dice Morin: «Una ciencia de la ciencia impone concebir el conocimiento de todo conocimiento en su enraizamiento a la vez cerebral, espiritual, noológico, cultural, social e histórico» (p. 62). Para realizar este enfoque -continúa Morin-, no solo necesitamos 
conocimientos más amplios y más ricos que los que disponemos; también debemos tener la capacidad de asociar lo que nuestro modo de conocimiento tradicional pone en disyunción.

La ciencia, de acuerdo con lo que expone Morin, no puede fiarse de las decisiones de un grupo de científicos que aprueba y desaprueba qué es y qué no es ciencia, tampoco se puede condicionar el saber científico a lo que se puede experimentar, o no, en los laboratorios especializados. El saber científico - como se ha venido exponiendo hasta el momento- y de acuerdo con lo que se puede interpretar del texto de Morin, está inscrito en la sociedad y requiere que en cada investigación exista una seria reflexión sobre los caracteres culturales de los conceptos y teorías como parte del quehacer social.

El observador no se puede disociar de la observación que realiza; Según Miguel Martínez Miguélez, el investigador entra en dicha observación y la perturba. Desde esta perspectiva el concepto de mundo objetivo que maneja la ciencia tradicional, es demasiado limitado, teniendo en cuenta, el ideal que maneja el basto campo de la cientificidad. Todo el saber se desenvuelve en el tiempo y en el espacio, según la ley de la causalidad, razón por la cual, el quehacer científico, desde la perspectiva diacrónica, histórica y cultural debe expandirse, flexibilizarse y problematizarse, frente a la realidad humana contingente que lo crea, reproduce y administra.

En la primera conclusión, podemos decir que la epistemología-según estos pensadores- tiene como finalidad las siguientes tareas: develar la manera como que se construyen las ciencias y los intereses varios que se expresan bajo formas más o menos sublimadas; identificar las estrategias que utilizan las ciencias para su institucionalización. Denunciar los condicionamientos históricos a los que se somete, mostrar el ocultamiento del sentido humano de las ciencias y la forma en que las ciencias son tributarias de factores filosóficos, religiosos, políticos, económicos, estéticos; por último, hacer explícito el carácter cultural implícito de las ciencias, para develar la crisis paradigmática por la que atraviesa el saber científico.

Desde las perspectivas que estudian las ciencias en relación con la sociedad y la cultura que defienden Thuillier, Blanco y Morin, se puede inferir la necesidad de reconocer el carácter social de las ciencias, así como la importancia que el investigador tiene en todas las etapas del proceso 
de investigación. También se puede evidenciar en el transcurso de la investigación, que las ciencias como producto de la historia humana están expuestas al continuo examen y en consecuencia, a la revolución paradigmática según como la concibe Kuhn, para motivar la dinamicidad de las prácticas científicas posteriores.

Un último asunto por mencionar es que la epistemología es un tipo de saber filosófico sobre las prácticas o actividades que tienen como resultado el conocimiento científico, y sobre las formas de validar dicho conocimiento desde el punto de vista interno y externo de la ciencia. Este tipo de saber se ha hecho desde perspectivas determinadas y acerca de disciplinas o ciencias específicas. Desde el punto de vista descrito, la epistemología no se puede concebir en singular sino como un conjunto de epistemologías. Estas perspectivas se refieren a un punto de vista que indaga por asuntos precisos; por ejemplo aplicar los principios de la teoría de la evolución al desarrollo y los avatares del conocimiento científico, o entender cómo ha tenido lugar la filogénesis de las estructuras del conocimiento, surgiendo así la epistemología evolutiva.

Otro caso lo representan las llamadas epistemologías regionales, se trata de las formas de validación del conocimiento que produce una disciplina determinada y no tienen la pretensión de extrapolar tales condiciones de validación a otros conocimientos o ámbitos disciplinares (González Lobo y otros, 1999, s.p). Un último ejemplo puede ser el de la epistemología histórica, esta perspectiva ve la ciencia centrándose en lo heurístico y en el desarrollo histórico no regular ni continuo, ni secuencial. Los epistemólogos de la historia, se posicionan en contra de los que llaman la pretensión reduccionista de la racionalidad logicista del neopositivismo, anteponiendo mejor la racionalidad histórica. Esta mirada tiene gran influencia de los estudios foucaultianos y se preocupa por los procesos de epistemologización, del dominio del saber y de cómo se alcanzan las normas de la cientificidad (Margot, 1977, p. 29).

En los apartados que siguen se presentarán las perspectivas de las llamadas epistemologías críticas, se retomarán como antecedentes la escuela de Frankfurt y los pensadores que en ella convergen y que han generado impacto en las reflexiones epistemológicas críticas póstumas. Se hará énfasis en las reflexiones sobre el conocimiento acerca de los dogmatismos creados en torno a la univocidad, neutralidad y universalidad de la filosofía de la ciencia, el problema de la 


\section{Epistemologías Críticas Feministas}

globalización y el capitalismo; así como los riesgos y consecuencias de estos dogmatismos para la dignidad humana.

\section{Crítica y autocrítica de las ciencias: La epistemología crítica y las epistemologías feministas}

A partir de las preguntas sobre la relación entre ciencia y sociedad existen diferentes escuelas y propuestas, ya que surgen innumerables problemas. Una de estas se refiere a cómo la ciencia y la epistemología deben ser críticas con su quehacer. Estas perspectivas se guían por principios como que las ciencias deben auto-examinarse constantemente, para evitar seguir alimentando los dogmatismos que no contribuyen para su dinamicidad en la actualidad, y que además deben incorporar como parte sustancial de su ejercicio investigativo, que las ciencias son una construcción diacrónica, que las bases del quehacer científico han estado enmarcadas en la historia y por ende en la sociedad.

Otro principio de las epistemologías críticas radica en la necesidad de tomar en serio la historia y la sociedad para comprender mejor el contexto del conocimiento científico, la expresión «ciencia y la sociedad», en el lenguaje científico, es sinónimo de perversión; pues a la sociedad siempre se le ha relacionado con la sabiduría popular, la especulación y la falta de rigurosidad metódica e investigativa, o con disciplinas que le restan objetividad a los resultados de investigación.

Ya se ha venido mencionando en el apartado anterior cómo la cultura, la historia y la sociedad permean las ciencias y cómo los autores, como Kuhn, Lakatos y Morin han encontrado en esta relación una oportunidad para ampliar el campo científico y para optimizar los esfuerzos en favor del conocimiento.

La relación entre ciencia y sociedad -como se mencionó anteriormente- fue una de las preocupaciones principales de la escuela de Frankfurt, Habermas, Horkheimer, Adorno y Marcuse comparten la crítica al crecimiento desmesurado de la racionalidad instrumental. La formulación de Horkheimer acerca de un preocupante aplastamiento de la razón objetiva (la que debe orientar a los hombres respecto a qué fines perseguir) por parte de la razón instrumental 
(que solo se ocupa técnicamente de ajustar la relación entre medios y fines), es un eje clave que orientará toda la producción teórica habermasiana. Según Boladeras (1996):

Habermas entiende por conocimiento al conjunto de saberes que acompañan y hacen posible la acción humana, siendo claro que la concepción objetivista, instrumental y aséptica que de la ciencia tiene el positivismo es algo muy limitado al lado de esa noción habermasiana [...] Para Habermas el positivismo ha desplazado al sujeto cognoscente de toda intervención creativa en el proceso de conocimiento y ha puesto en su lugar al método de investigación (p. 27).

Boladeras, haciendo referencia a Habermas, propone que el quehacer de la ciencia es un ejercicio propio de la acción humana y por esta razón es un trabajo constante de construcción, cuando se habla de razón instrumental, la creatividad, el examen constante y el asombro quedan por fuera del ejercicio epistémico, no hay producción científica si la ciencia no es humana y mudable.

La teoría crítica como principal cuerpo teórico de la escuela de Frankfurt, estableció algunas de las bases que van a retomar las ECF, abriendo la posibilidad de nutrir e incorporar críticas nuevas como el sesgo androcéntrico, manifestado en los supuestos de universalidad, neutralidad, y objetividad de la ciencia. En este contexto se ubican diferentes reflexiones sobre la capacidad transformadora del conocimiento en la sociedad; autores y autoras contemporáneas se han inspirado en el pensamiento crítico para problematizar la relación saber-ciencia, con el fin de optimizar la utilidad del conocimiento científico, y para destacar la responsabilidad social de las ciencias en el bienestar de los individuos en el marco de la globalización y la homogenización de las sociedades. Ejemplos de estas reflexiones son muchas, como las propuestas de Santos Boaventura de Sousa en los textos Introducción: las epistemologías del sur y la "Crítica de la razón indolente”; Lucia del Moral, en el artículo En transición. La epistemología y filosofía de la ciencia ante los retos de un contexto de crisis multidimensional y el texto de Edgar Morin, Ciencia con Conciencia, que se refiere a la responsabilidad social de la ciencia, el problema de las consecuencias del pensamiento científico, y a la llamada crisis epistemológica de la ciencia moderna. 
Santos (2000) en el texto Las epistemologías del sur dice que esta perspectiva epistemológica reflexiona «creativamente sobre esta realidad para ofrecer un diagnóstico crítico del presente que, obviamente, tiene como su elemento constitutivo la posibilidad de reconstruir, formular y legitimar alternativas para una sociedad más justa y libre» (p. 14). El interés de transformar la sociedad a través del conocimiento y el conocimiento a través de la sociedad es fundamental para contextualizar el saber, para humanizarlo.

Del Moral (2012, propone que el saber científico parte de los espacios y las prácticas comunitarias, ya que estas contribuyen a las reflexiones y debates sobre la sostenibilidad de la vida y la consecución de vidas vivibles. Ella resalta la importancia que la vida cotidiana y la reflexión que los individuos hacen sobre ella, tiene y ha tenido en el quehacer científico (p. 74).

Este pensamiento se puede rastrear también en la epistemología crítica en América Latina además de las epistemologías mencionadas-. El pensador colombiano Carlos Gallegos ${ }^{5}$ (2012), define la epistemología crítica en América Latina como una propuesta epistémica, que entiende:

La construcción del conocimiento como un proceso centrado en la recuperación de las perspectivas históricas planteadas por los sujetos subalternos, por sus demandas en el presente, así como sus expectativas frente al futuro. Siempre en el marco de una disputa por la definición de su identidad, su colocación social y su práctica (p. 15).

Gallegos dice que la epistemología en América Latina es una propuesta nacida de la necesidad de reflexionar sobre cómo construir y cómo producir conocimiento científico opuesto a los paradigmas neoliberales dominantes. Esta propuesta es desarrollada por científicos sociales latinoamericanos influidos teórica y analíticamente por Karl Marx, Friedrich Engels, Antonio Gramsci, Theodor W. Adorno, Max Horkheimer, Herbert Marcuse, Ernst Bloch, Fernand Braudel, Walter Benjamin, Alfred Schütz y George Gurvitch también por Michel Foucault, Cornelius Castoriadis, Pierre Bourdieu e Immanuel Wallerstein, entre los autores más importantes. Algunos de los autores latinoamericanos identificados en esta perspectiva son

\footnotetext{
${ }^{5}$ Profesor Titular de la Licenciatura en Ciencias Políticas y Administración Pública en la UNAM. Facultad de Ciencias Políticas y Sociales.
} 


\section{Epistemologías Críticas Feministas}

(...) Luis Villoro, Pablo González Casanova, Sergio Bagú, Aníbal Quijano, Walter Mignolo, Emir Sader, Hugo Zemelman, Enrique Dussel, Félix Gustavo Schuster, Edgardo Lander, Gregorio Castro, Arturo Escobar, Jorge Vergara, Orlando Fals Borda, Armando Bartra Borda; todos inscritos en una lógica de deconstrucción-construcción; desarticulación-articulación de las formas del pensamiento para superar lo que entendemos aquí como colonialidad del saber (Gallegos, 2012, p. 25-26).

Esta perspectiva, según Gallegos, enmarca de manera general las pretensiones de la epistemología crítica y muestra cuáles son los elementos relevantes que los estudiosos del conocimiento crítico tienen en cuenta. Por ejemplo, acoger todas las voces que reflexionan sobre el conocimiento sin importar si acogen el método científico; superar los dogmatismos creados en torno a la univocidad, neutralidad y universalidad de la filosofía de la ciencia, el problema de la globalización y la capitalización de la dignidad humana entre otras.

En conclusión, las epistemologías críticas son un alto en el camino de las epistemologías clásicas, invitan a la reflexión, al examen constante y a reinterpretar la pregunta ¿Cuál debe ser la finalidad del conocimiento? ¿Quién hace el conocimiento? y ¿Para qué los individuos crean conocimiento? De esta forma, la ciencia tiene que volver a dejarse guiar por la razón humana y sus necesidades y no a la inversa, la ciencia debe hacerse en función de la humanidad y no la humanidad en función de la ciencia.

Las epistemologías críticas han querido resaltar el papel que juega la sociedad y la historia en las reflexiones epistemológicas y en el quehacer científico. La tarea de humanizar la filosofía de la ciencia, de recuperar las perspectivas históricas por y desde los sujetos subalternos, las demandas en el presente y las expectativas frente al futuro hace parte de las características que conforman a las epistemologías críticas y como vamos a ver las ECF.

Estas problemáticas serán retomadas por algunas epistemólogas, que también van a contribuir en la crítica y en la enunciación de posibles alternativas que beneficien el ejercicio teórico y práctico del conocimiento científico. 


\section{Epistemologías Críticas Feministas}

\section{Reflexiones feministas sobre la epistemología}

Otra línea de reflexión sobre la relación entre la ciencia y la sociedad es aquella trazada por los feminismos. El feminismo académico europeo desde la llamada primera ola ya reflexionaba sobre cómo la filosofía se refería a las mujeres, sobre sus capacidades para educarse y producir conocimiento, así lo señalaba la filósofa y escritora británica Mary Wollstonecraft (1759 - 1797), considerada una de las precursoras de la filosofía feminista, conocida sobre todo por su libro Vindicación de los derechos de la mujer (1792) en el que reivindica el derecho al trabajo, a la educación y a la emancipación económica.

Los feminismos han continuado realizando este tipo de denuncias, pero además, las feministas filósofas y científicas, empezaron a cuestionar la ciencia y los planteamientos epistemológicos. Las epistemologías feministas son un conjunto heterogéneo de posturas, que presentan como común denominador el cuestionamiento de las ciencias en tanto androcéntricas y la crítica de las bases epistemológicas y metodológicas que las sustentan. Las reflexiones epistemológicas feministas problematizan asuntos como los de la objetividad, la universalidad, la neutralidad, y la ahistoricidad de la ciencia; ubicando en primer plano la presencia de valores socio-culturales y de género en el proceso de investigación, así como en las dinámicas de institucionalización, validación del conocimiento científico y acceso a la producción de este conocimiento, lo que Sandra Harding llamará estructura social de la ciencia.

Harding en el texto Ciencia y feminismos, explica en varios momentos, citando algunos pensadores de la ciencia, por qué los feminismos empiezan a reflexionar sobre la ciencia y sobre la filosofía de la ciencia. La filósofa resalta que una de las razones por las que han tenido que emprender esta larga y agotadora lucha es que la estructura social de la ciencia reproduce la estructura social de discriminación y la división social del trabajo según el género.

Harding muestra el lugar subordinado que históricamente han ocupado las mujeres en la ciencia, su invisibilidad en la historia su arduo recorrido en aras de ser reconocidas como sujetos de conocimiento y como sujetos útiles para la economía a través del trabajo. 
Harding quiere mostrar que pese a los logros del ingreso de las mujeres a la universidad, del aumento del número de mujeres en la ciencia, el prestigio y tipo de empleo nunca fue igual al de los hombres. Vale mencionar que en Norteamérica entre 1820 y 1920, según referencia de Harding, hombres y mujeres contribuyeron a esta situación como consecuencia de la convergencia parcial de dos tendencias importantes, aunque esencialmente independientes: Harding, retomando a Rossiter, comenta: «Una tendencia se puso de manifiesto en la aparición de la educación superior y en las mayores posibilidades de empleo para las mujeres de clase media» (p. 53); la otra tendencia, comenta Harding «podía observarse en 'el crecimiento de la burocratización y la profesionalización de la ciencia y la tecnología norteamericana» (p. 54).

La primera tendencia, según la autora, permitió a las mujeres alcanzar los tipos de educación científica reservados antes exclusivamente a los hombres, conseguir trabajo en el medio científico. La segunda tendencia garantizaba que la relación entre la educación de las mujeres, por una parte, y sus oportunidades de empleo y de prestigio, por otra no fuese igual a la de los hombres como administradores de la ciencia.

La inclusión de las mujeres en la educación superior aunque hubiese sido por conveniencia política y económica $^{6}$, fue una gran oportunidad para que las mujeres accedieran de alguna forma a la vida pública. Harding resalta que los estudios de Rossiter, muestran que estos logros no obtuvieron continuidad, porque las pocas mujeres que se habían formado en las universidades fueron expulsadas de los puestos de prestigio que habían ocupado.

Pese al ingreso de las mujeres a la universidad y de ser aceptadas en el campo laboral profesional, la división científica del trabajo seguía reproduciendo la subordinación de las mujeres, desvaneciéndose la posibilidad de que la ciencia fuera democrática. Harding dice

\footnotetext{
${ }^{6}$ Una de las razones más apremiantes para dar más oportunidades educativas y laborales a las mujeres fue el fenómeno del enorme incremento, en Europa y en los Estados Unidos, de mujeres 'redundantes' o 'superfluas' como se denominaba en la Inglaterra del siglo XIX a las mujeres solteras. En los Estados Unidos, las muertes habidas en la Guerra Civil supusieron la eliminación de tres millones de hombres casados o con posibilidades de casarse [...] Estos enormes desequilibrios entre los sexos dejaron a millones de mujeres, muchas de ellas sostenes únicos de sus familias (Harding, 2006, p. 55).
} 


\section{Epistemologías Críticas Feministas}

Incluso cuando ascendió el nivel educativo de las mujeres y se ampliaron sus fundamentos fuera del hogar, se consideraba que éstas constituían solo un conjunto reducido de actividades "femeninas", estereotipo que las vinculaba y las limitaba a unos tipos de sentimientos y conductas, suaves, delicados, emocionales, no competitivos y asistenciales. Al mismo tiempo, el estereotipo de la "ciencia" se contemplaba, retóricamente, casi como el polo opuesto: duro, riguroso, impersonal, masculino, competitivo y no emocional. Por tanto, en términos de las idealizaciones retóricas de los estereotipos del siglo XIX, las mujeres científicas eran una contradicción en sus propios medios (Rossiter como se citó en Harding, 1996, p. 54).

Harding explica cómo las mujeres científicas quedan subordinadas a causa de cualidades naturales que las incapacitaba frente al quehacer científico, estaban atrapadas entre dos estereotipos que casi se excluían entre sí: «como científicas, eran mujeres atípicas; como mujeres eran científicas raras» (p. 54). Es más, continúa, -Harding apoyándose en Rossiter (1996)-:

Este elemento conceptual significaba que gran parte de la historia de las mujeres en la ciencia no se situaría en el marco de la realidad objetiva, de lo que las mujeres concretas pudieron hacer o hicieron, sino, de forma subrepticia, en el terreno psíquico de las imágenes y de los estereotipos sexuales con su propia lógica interna. (p. 54).

Las reflexiones de Rossiter -y las nuestras- sobre las razones por las que las mujeres han tenido que emprender esta larga y agotadora lucha para intentar acabar con la discriminación del acceso a la ciencia, indican que aunque este fue un período de gran fluidez e innovación como comenta Harding, en el que fueron desarrollándose nuevas funciones y oportunidades a medida que surgían hombres capaces de aprovecharlas, las mujeres se encontraban una y otra vez con que las posibilidades en expansión que ofrecía la ciencia les estaban vedadas.

Otra de las razones por las que los feminismos empezaron a reflexionar y criticar las ciencias es que así como en la estructura social de la ciencia se reproduce la estructura social de género, la ciencia tiene un sesgo androcéntrico, que se manifiesta en la definición de problemas, teorías, 
marcos teóricos, que reproducen los estereotipos de género. Sandra Harding muestra la necesidad de reducir de manera radical los estereotipos de género si se busca algún tipo de igualdad de oportunidades para las mujeres en la ciencia. Este tema se desarrollará de manera más precisa en el capítulo II de este trabajo.

En conclusión, los feminismos empiezan a reflexionar sobre la ciencia y sobre la filosofía de la ciencia, primero, por la evidencia de que a pesar del acceso a la educación y al sistema laboral se sigue evidenciando una subalternización y una división del trabajo desigual. En segundo lugar, porque se dieron cuenta de que la ciencia reproduce estereotipos e inequidad de género en los problemas que plantea, en las teorías y en los resultados de las investigaciones científicas. Y en tercer lugar por la necesidad de mantener la autocrítica en las ciencias y en los movimientos feministas.

Una de las fortalezas de las epistemologías críticas feministas, que Harding hace explícita en el texto Ciencia y Feminismo, -y que Thuillier y los seguidores de la teoría crítica ya habían mencionado-. Es la necesidad de que el conocimiento mantenga el carácter autocrítico como herramienta fundamental para evitar caer en dogmatismos, la epistemología debe cuestionar constantemente las bases teóricas que definen el acceso al conocimiento y estar abierta a las reflexiones e ideas emergentes convencionales y no convencionales. En el siguiente apartado se presentan algunas de las ECF.

\section{Las epistemologías críticas feministas}

Siguiendo a la epistemóloga Sandra Harding (1996), podemos identificar las teorías epistemológicas críticas feministas que se han venido estructurando en los feminismos y que también han sido objeto de análisis y crítica por parte de la filósofa, entre ellas:

1) Las teorías integracionistas, que denuncian la presencia de estereotipos discriminativos y sesgos sexistas en la ciencia, proponiendo soluciones para el desarrollo de una práctica científica genéricamente equilibrada. Las recomendaciones se desarrollan en dos planos: En el plano institucional o externo: el desarrollo de políticas que permitan la incorporación de mujeres al 


\section{Epistemologías Críticas Feministas}

trabajo científico y la supresión del denominado "techo de cristal" referido a la imposibilidad femenina de obtener puestos de mayor jerarquía en los institutos y asociaciones científicas. (Barberá, 2004) En el plano interno, el inherente a la práctica científica en particular, se critica las generalizaciones inapropiadas basadas en el prototipo de varón blanco occidental y se sugiere el estudio de problemáticas femeninas y un proceso de revisión metodológica con relación a los procesos de muestreo. Desde ésta perspectiva los sesgos sexistas son "errores científicos" que pueden ser corregidos. Tal postura no plantea rupturas con la concepción científica estándar en la medida en que no se pone en tela de juicio a las normativas científicas convencionales, sólo se critica su inadecuada aplicación. Los puntos objetables a ésta postura provienen de los feminismos que adoptan una perspectiva crítica y construccionista (Martínez, 2003), los cuales le imputan la adhesión a inapropiados presupuestos tradicionales de "hacer ciencia" solidarios a un modelo patriarcal y jerárquico de sociedad: la neutralidad valorativa, la objetividad, el dominio de la naturaleza,

2) La teoría del punto de vista, dicha posición parte de presupuestos marxistas estableciendo que por su lugar marginal y dominado en las estructuras jerárquicas sociales, las mujeres poseen un “privilegio epistemológico" (p. 3).

3) Los empirismos feministas, nacen de una idea que no es en absoluto patrimonio del feminismo. El sujeto del conocimiento se percibe como un individuo histórico particular cuyo cuerpo, intereses, emociones, razón, están constituidos por su contexto histórico concreto. Estas cualidades del sujeto son relevantes para la epistemología, y para el rol que desempeña como investigador, siempre visto como "situado" (Haraway, 1991, p. 4).

4) Las epistemologías posmodernas, critican la idea de las identidades homogéneas e inmutables, en especial las referidas al género; para ellas, las identidades se construyen y se alteran de acuerdo con otras posiciones sociales como la etnia, la edad y el contexto socio-histórico. También desconfían de las teorías universalistas y de las verdades absolutas así como del progreso ilimitado de la razón humana. 
Nos encontramos entonces con un abanico de epistemologías feministas que pese a sus diferencias, coinciden en que las prácticas científicas y profesionales están inmersas en valores. De acuerdo con las mismas, una disciplina no debiera estudiarse solo desde la perspectiva de sus productos o de la relación entre los sujetos y los objetos, como si tal episteme fuese una unidad separable e independiente del universo sociopolítico en el cual se inscribe, debería emprenderse el examen crítico desde sus mismos presupuestos. Las epistemologías feministas asumen que los valores no cognitivos o contextuales influyen en el lenguaje de la ciencia, en las metáforas, en los problemas elegidos, en los métodos de investigación y de justificación de las teorías, en los fines perseguidos e incluso en el propio contenido de las teorías científicas.

La reflexión crítica sobre la ciencia desde la perspectiva feminista cuestiona la naturaleza misma del conocimiento científico y el poder que otorga su nombre «ciencia» a las disciplinas que adoptan el método y que definen su objeto de estudio. Cuestiona el supuesto de que las ciencias nada tengan que ver con el género y con las mujeres, así como los procedimientos empleados para llegar a los supuestos de verdad científicos.

Un aspecto clave en las relaciones entre las epistemologías tradicionales de la ciencia y los análisis feministas, consiste en disponer de una teoría de la investigación científica que ponga de manifiesto la dimensión ideológica de la construcción del conocimiento; y a la vez, que ofrezca criterios para evaluar comparativamente las teorías científicas y los programas de investigación, teniendo en cuenta en especial el papel del género y los estereotipos de género. Aunque no se pueda hablar de la filosofía feminista de la ciencia como un todo homogéneo, existen corrientes y tendencias diferentes, todas ellas conscientes de la ubicuidad del género y de su papel como categoría analítica.

La importancia que se le atribuye a las epistemologías críticas feministas recorre una escala gradual que abarca la aparición del género en el contexto de descubrimiento; en la ciencia considerada como actividad social; en los métodos, las técnicas y el procedimiento general de la ciencia; en el contenido mismo de las teorías científicas -en especial en las que versan sobre los seres humanos-; y en los procedimientos de evaluación y validación de las teorías mismas. 


\section{Epistemologías Críticas Feministas}

El interés de las epistemologías críticas feministas, además, encarna el planteamiento de la autocrítica que se mencionaba en líneas anteriores, no solo con el fin de tener como punto de referencia el examen de las epistemologías tradicionales de la ciencia, también las epistemologías feministas y las epistemologías críticas feministas. La crítica epistemológica feminista permite identificar las falencias existentes en la filosofía de la ciencia, como el sesgo androcéntrico con que se halla velada, así, también debe contribuir en la construcción de una epistemología crítica feminista libre de dogmatismos, con la apertura necesaria para afrontar y aceptar los cambios que sean necesarios para mejorar su fidelidad frente al saber. Harding junto a otras filósofas de la ciencia, denuncia que la ideología androcéntrica de la ciencia contemporánea:

Plantea como necesarios, como hechos o como ambas cosas, un conjunto de dualismos cultura frente a naturaleza; mente racional frente a cuerpo prerracional y emociones y valores irracionales; objetividad frente a subjetividad; público frente a privado-, relacionando después a los hombres y la masculinidad con los primeros elementos y a las mujeres y la feminidad con los segundos de cada par (Harding, 1996, p. 119).

Esta dicotomización -continúa Harding - constituye una ideología en el sentido fuerte del término: «en contraste con las creencias falsas, sesgadas a favor de unos valores, que carecen de poder social, estas creencias estructuran las políticas y prácticas de las instituciones sociales, incluida la ciencia» (p. 119).

¿Cuáles serían los cambios en la forma de percibir el conocimiento científico, si se planteara una epistemología crítica feminista? La tarea fundamental de las ECF no es montar un modelo epistémico que sustituya el paradigma dogmático del androcentrismo por un paradigma dogmático feminista, que justifique a las mujeres como las únicas capaces de estructurar y proponer el único conocimiento verdadero. El objetivo de la búsqueda feminista del saber afirma Harding- consiste en elaborar teorías que representen con precisión las actividades de las mujeres como actividades sociales y las relaciones sociales entre los géneros como un componente real -importante desde el punto de vista explicativo- de la historia humana. El interés de esta pretensión suscita dice Harding (1996): 
La necesidad de teorizar sobre el género como categoría analítica cuando se identifican diferencias de forma de pensar entre hombres y mujeres con respecto a la reproducción y a las tecnologías reproductivas, cuando se plantean cuestiones sobre la posibilidad de que el mismo tema de la diferencia de sexo suscite mayor interés entre los hombres que entre las mujeres, cuando se sugiere que el enfoque del método científico sobre las diferencias pueda tener que ver con el androcentrismo que rodea esos problemas y con la posibilidad de que la preocupación de la biología, la antropología y la sociología por las relaciones interactivas entre organismos y entre organismos y ambientes, refleje formas específicamente femeninas de conceptuar relaciones muy abstractas (p. 30).

La cuestión que pretende mostrar Harding es la dificultad que existe a la hora de pretender conocer que significa desempeñar el rol de hombre o de mujer desde la posición contraria. Es muy diferente el estudio de las mujeres hechas por ellas mismas, que el estudio de las mujeres realizado por los hombres y viceversa. La desconfianza siempre está presente cuando un sujeto debe tomar la posición del objeto, porque se expone a que otro juzgue lo que es, incluso sin él como sujeto, saberlo. Los hombres en algunas ocasiones han utilizado los estudios sobre las mujeres para devaluar la naturaleza y las capacidades que ellas poseen, para continuar alimentando la falsa idea de la superioridad masculina sobre la femenina, tergiversando la información en favor de los estereotipos que la historia de los hombres continúa justificando.

Para acercarse a la categoría analítica del género, es indispensable tener acceso a la perspectiva que desde el mismo género se han venido realizando, teniendo en cuenta que las diferencias son evidentes entre lo masculino y lo femenino, entre los contextos y culturas. Cada uno -hombre y mujer- perciben la realidad y los problemas de acuerdo con los prejuicios que poseen y elaboran perspectivas distintas que los pone en estados axiológicos diferentes; por lo que tener en cuenta la subjetividad de los sujetos, sobre lo que piensan y sienten es esencial para descubrir algo de lo que significa estar en la posición de un hombre y una mujer.

Sandra Harding, Pierre Thuillier, Edgar Morin entre otros pensadores, afirman que la ciencia es una construcción social, que no aparece de golpe. Por el contrario, ella se va edificando, se va 
construyendo, en el proceso de delimitación y determinación de su propio objeto y según específicos instrumentos conceptuales sobre los cuales se estructura el saber. En este sentido, la ciencia es la construcción de su contenido material, según ciertos caminos o métodos que genera el pensamiento acerca de ese objeto, porque la ciencia se va edificando y especificando en tanto que resultado de determinadas condiciones materiales, sociales y formales.

La construcción del saber no es imparcial, la ciencia tampoco lo es. La razón principal es que no se puede suprimir la subjetividad, porque todo investigador está inmerso en una cultura, en una realidad específica que condiciona consciente o inconscientemente cualquier tipo de apreciación que emita; no se puede ser imparcial por completo, tampoco pretender que el sujeto pueda despojarse de todos los prejuicios adquiridos en el transcurso de la vida, sería como pretender determinar el gusto por la misma música a un grupo culturalmente heterogéneo.

Un eje que articula las críticas feministas como reacción frente a algunos postulados de la ciencia tradicional, es el sesgo androcéntrico de la investigación; por ello, la importancia de identificar y demostrar que en las prácticas científicas convencionales existe un sesgo androcéntrico evidente, tanto en los conceptos y las categorías que se utilizan en la indagación científica, como en los marcos teóricos en los que se inscriben (Haraway, 1995; Harding, 1995b; Fox, 1991).

Esto tiene una doble incidencia, por un lado provoca discriminación en las mujeres para el acceso a la ciencia, y por otro, es la causa de la «mala ciencia»y de los resultados «sesgados», precisamente por la posición subjetiva e interesada del investigador, condicionada por una posición y rol determinado. Si lo anterior es corroborable, entonces las críticas epistemológicas no están muy lejos de encontrar algunos de los fundamentos que permitan respaldar las tesis sobre la presencia del androcentrismo en el campo científico.

En conclusión, entendemos por epistemologías críticas feministas, aquellas formas de conocimiento que denuncian que el saber y la ciencia no son imparciales. Las ECF aunque variadas, se concentran en hacer una evaluación crítica de las ciencias, de sus presupuestos, en especial de los valores sociales e individuales que influyen en el lenguaje de la ciencia, en los 


\section{Epistemologías Críticas Feministas}

marcos teóricos, en los problemas relevantes así como en la justificación, como también en los resultados de las investigaciones.

Las ECF se distinguen por la intención de desvelar la dimensión ideológica de la construcción del conocimiento, en especial el papel del género y de los estereotipos de género. La ciencia es una construcción social resultado de condiciones materiales, sociales y formales específicas, por eso las ECF proponen como procesos epistemológicos alternativos la descentralización del saber, el carácter social del conocimiento, la contextualización del objeto, y el examen constante de la ciencia como posibilidad de innovación y progreso. Las ECF son campos epistémicos que muestran alternativas para llegar al conocimiento a partir del examen y el autoexamen constante del conocimiento científico vigente.

\section{Críticas de Sandra Harding a las críticas feministas}

Sandra Harding presenta, en el texto Ciencia y Feminismo, tres críticas feministas con las que va a intentar resolver lo que Harding denomina una paradoja epistemológica. Según la filósofa esta trata sobre la aparente contradicción que existe, sobre pedir objetividad a la ciencia, desde la subjetividad del feminismo. Para tal efecto, la autora realiza una breve descripción de cada una de las críticas, en las que va a enmarcar las soluciones que se han dado en torno a la paradoja. Entre ellas encontramos: el empirismo feminista, el punto de vista feminista y el postmodernismo feminista.

«El empirismo feminista sostiene que el sexismo y el androcentrismo constituyen rasgos sociales corregibles mediante la estricta adhesión a las normas metodológicas vigentes de la investigación científica» (Harding, 1996, p. 23). El planteamiento de esta crítica según la autora, es mostrar que se puede corregir la perspectiva de los investigadores siempre y cuando quienes realizan las observaciones y análisis no se separen de los lineamientos estrictos que el método científico establece. Esta solución a la paradoja resulta atractiva, porque deja intactas las normas metodológicas vigentes en la ciencia. «Mediante este tipo de argumento, es más fácil conseguir 


\section{Epistemologías Críticas Feministas}

que se acepten las reivindicaciones feministas, porque suscriben el problema a la mala ciencia, sin extenderlo a la ciencia en uso (Harding, 1996, p. 23-324).

Para la filósofa, la sociedad está cegada por un cúmulo de información que no ofrece perspectivas de diversos ángulos, solo se muestra lo que las ciencias androcéntricas han permitido que se pueda ver, sin embargo, los movimientos de las mujeres, así como otros movimientos de liberación social se han entregado a la tarea, de retirar los obstáculos que han limitado el acceso a una perspectiva más amplia del saber que no solo esté centrada en la historia de los hombres, en la ciencia de los hombres y en las sociedades económicamente solventes. Sino que permita el acceso al trabajo académico, científico de las mujeres y de otras comunidades subalternas.

Para las empiristas feministas son las mujeres las únicas que se pueden percatar del sesgo androcéntrico de las ciencias, pues son ellas quienes han vivenciado la discriminación en los procesos académicos de la historia y no los hombres.

Para Harding, que el empirismo feminista afirme que el problema de la ciencia consiste más en un problema metodológico o del mal uso del método científico, implica una gran dificultad si aquello que se busca es transformar el escenario androcéntrico con que se ha elaborado la ciencia tradicional. Entonces la pregunta sería: ¿cómo cambiar un resultado si el método es el mismo?

Otra cuestión importante que se puede identificar en el empirismo feminista es que los estudios solo los realizarían las mujeres, pues ellas, serían las únicas capaces de identificar los sesgos androcéntricos que están presentes en la ciencia. Para Harding, el empirismo feminista subvierte profundamente el empirismo.

Se supone que la identidad social del investigador es irrelevante para la 'bondad' de los resultados de su investigación. Se presume que el método científico es capaz de eliminar los sesgos debidos al hecho de que los investigadores concretos sean blancos o negros, chinos o franceses, hombres o mujeres. Pero el empirismo feminista sostiene que es más probable que las mujeres (o las feministas y los feministas, sean mujeres y hombres), como 
grupo obtengan más resultados no sesgados y objetivos que los hombres (o los no feministas y las no feministas) como grupo. (Harding, 1996, p. 24).

Harding retoma en esta cita algunas de las críticas realizadas anteriormente. En primera instancia, cuestiona la imparcialidad del investigador frente a su objeto de estudio, para la filósofa el científico no se desliga del objeto de observación y no puede evitar que se contamine de los prejuicios con los que habita en su vida cotidiana. En segunda instancia, cuestiona también la presunción de la ciencia tradicional sobre la capacidad que el método científico posee, gracias a la perspectiva neutral de sus investigaciones, con lo que descarta la posibilidad de acoger sesgos que impidan la observancia de la objetividad pura. En tercer lugar, cuestiona la imposibilidad de poder afirmar que el hecho de ser feminista es suficiente para ofrecer resultados objetivos y libres del sesgo androcéntrico que aquellos que no lo son. En cuanto a la veracidad del método científico dice Harding (1996):

Aunque el empirismo sostiene que el método científico es suficiente para explicar los incrementos históricos de objetividad del panorama del mundo que presenta la ciencia, podemos afirmar que la historia muestra otra cosa muy diferente. Son los movimientos de liberación social los que más han aumentado la objetividad de la ciencia y no las normas de la ciencia misma cuando se han puesto en práctica ni cuando los filósofos las han reconstruido racionalmente (p. 24).

Para la autora no es el método científico el que ha ofrecido la posibilidad de incrementar la objetividad del saber. Uno de los elementos claves para la reproducción y sostenimiento del poder han sido las ciencias y consecuentemente el método con que se han elaborado, desde donde se han formulado los problemas y los campos relevantes de investigación, omitiendo un alto porcentaje de acontecimientos que se dibujan entre las mujeres, campesinos, niños. «Pero el empirismo insiste en que sus normas metodológicas solo se aplican en el 'contexto de justificación' - para la comprobación de hipótesis y la interpretación de los datos- y no en el 'contexto de descubrimiento' cuando se identifican y definen los problemas» (Harding, 1996, p. 24). Con lo anterior -comenta Harding- se confirma que una poderosa fuente de sesgo social se escapa por completo del control de las normas metodológicas de la ciencia. 


\section{Epistemologías Críticas Feministas}

Por último, concluye Harding (1996): «El feminismo trata de reformar lo que se percibe como mala ciencia, llamando nuestra atención sobre unas profundas incoherencias lógicas y sobre lo que paradójicamente, podemos llamar imprecisiones empíricas de las epistemologías empiristas» (p. 24).

El punto de vista feminista según Sandra Harding tiene su origen en el pensamiento de Hegel sobre la relación entre el amo y el esclavo así como en la elaboración de este análisis que aparece en los escritos de Marx, Engels y el teórico marxista húngaro G. Lukacs. Según la filósofa, esta propuesta a la solución de la paradoja, consiste, en favorecer la posición subyugada de las mujeres, como una posibilidad para llegar al conocimiento de manera más completa y menos perversa que la posición cómoda y dominante de los hombres.

El feminismo y el movimiento de las mujeres aportan la teoría y la motivación para la investigación y la lucha política que pueden transformar la perspectiva de las mujeres en un 'punto de vista' - un fundamento, moral y científicamente preferible, para nuestras interpretaciones y explicaciones de la naturaleza y la vida social- (Harding, 1996, p. 2425).

La paradoja de las epistemologías críticas feministas consiste en que la ciencia contribuya de manera equitativa en la transformación social y Harding, en líneas anteriores enuncia la importancia de fundamentar moralmente el quehacer científico, libre de cualquier sesgo que evite interpretar y explicar la naturaleza y la vida social.

Sin embargo, para ella, aunque esta tentativa de solución a la paradoja epistemológica evita los problemas que plantea el empirismo feminista, también genera algunas tensiones. Por ejemplo que «quienes están apegados al empirismo se mostrarán muy reacios a aceptar la idea de que la identidad social del observador puede ser una variable importante con respecto a la objetividad potencial de los resultados de la investigación» (Harding, 1996, p. 25). 
Para las representantes del punto de vista feminista, todo conocimiento se genera en un contexto específico. Es esencial el reconocimiento de la intención del investigador frente al ejercicio científico. Pero desde el punto de vista estratégico, asevera Harding (1996), «esta explicación de la mayor adecuación de las proposiciones feministas es menos convincente, salvo para quienes ya están convencidos; es muy improbable que los científicos naturales o los partidarios de la ciencia natural de ambos géneros acepten esta postura» (p. 25).

El conocimiento que ha elaborado la ciencia tradicional en manos de los hombres, ha sido adaptado a los dispositivos de dominación con que se presentan los hombres frente al conocimiento y a las mujeres. Las problemáticas abordadas por la ciencia se refieren a un sector parcial del cúmulo de problemas que se presentan en la sociedad, exponiendo la objetividad del saber y la confiabilidad de la ciencia en pro de beneficios sexistas poco confiables. las mujeres por su parte, en ese estado de vulnerabilidad tiene a su disposición una perspectiva vivencial mucho más amplia, en tanto que no existen condicionamientos para percibir el panorama real y marginal que se ha venido escondiendo, que articulado con la historia, genera una mirada más completa de lo que es o debería ser la ciencia.

Harding muestra lo desgastante que resulta pretender cambiar en las investigaciones científicas los criterios de neutralidad y de objetividad. La autora enuncia tres problemas que retomará como críticas el postmodernismo feminista ¿Acaso debe haber puntos de vista feministas negros y blancos, de clase trabajadora y de clase profesional, norteamericanos y nigerianos? ¿Acaso el proyecto del punto de vista feminista está aún basado con demasiada firmeza en la alianza, históricamente desastrosa, entre el saber y el poder, característica de la época moderna? «Este tipo de consideración nos lleva al escepticismo posmodernista» (Harding, 1996, p. 25).

Debemos señalar que los enfoques epistemológicos precedentes parecen afirmar que la objetividad nunca ha podido ni podrá incrementarse mediante la neutralidad respecto a los valores. En cambio, los compromisos con los valores y proyectos antiutilitarios, antielitistas, participativos y emancipadores sí aumentan la objetividad de la ciencia (Harding, 1996, p. 26). 


\section{Epistemologías Críticas Feministas}

Aquí nos muestra Harding que las prácticas de la ciencia tradicional por siglos, han logrado naturalizar criterios epistemológicos que por más que se intente evidenciar la falta de confiabilidad a la sociedad, son difíciles de reemplazar. Generar conciencia frente a la inexistente objetividad absoluta es un trabajo que implica mayor esfuerzo y compromiso no solo desde los feminismos, sino desde los diversos entes epistémicos y científicos. Harding afirma que las investigadoras científicas:

No dicen nunca que los enunciados sexistas y los antisexistas sean igualmente aceptables que pueda darse el mismo valor a la idea de que la situación de las mujeres sea una cuestión primordialmente biológica y a la que se trata de una cuestión primordialmente social-, o a la idea de que 'lo humano' sea, a la vez, idéntico y no idéntico a 'lo masculino'. En algunos casos, la evidencia con respecto a los enunciados feministas frente a los no feministas puede no ser concluyente y no cabe duda de que muchos enunciados feministas que hoy parecen evidentemente seguros acabarán siendo abandonados cuando se obtengan nuevas pruebas y se construyan mejores hipótesis y conceptos (Harding, 1996, p. 25-26).

La filósofa deja claro que la intención del punto de vista no pretende al igual que la ciencia tradicional, generar un modelo de ciencia único, e incuestionable, por el contrario, deja clara su postura frente a las ciencias, de que todo saber está expuesto al cambio y a la crítica, que en últimas es lo que ha permitido a lo largo de la historia, una construcción del saber medianamente aceptable.

El postmodernismo feminista según la filósofa Sandra Harding, «niega los supuestos en los que se basan el empirismo feminista y el punto de vista feminista, aunque también aparecen en el pensamiento de estas teóricas las tensiones del escepticismo postmodernista» (1996, p. 26). Las feministas postmodernistas junto a otros filósofos comparten un profundo escepticismo respecto a los enunciados universales sobre la existencia, la naturaleza y las fuerzas de la razón, el progreso, la ciencia el lenguaje y el sujeto/yo. 
Este enfoque exige utilizar un fundamento adecuado para investigar las fragmentadas identidades que crea la vida moderna: feminista-negra, socialista-feminista, mujeres de color. Requiere buscar la solidaridad en nuestra oposición a la peligrosa ficción de lo exclusivamente ‘humano' naturalizado y esencializado, y a la deformación y explotación perpetradas en nombre de esa ficción (Harding, 1996, p. 26).

Aquí podemos identificar algunos elementos relevantes de la posmodernidad; en primer lugar el rechazo frente a algún método o fundamento específico para la investigación; en segundo lugar, la oposición a las estructuras, ideas y teorías que se han universalizado, provenientes de la modernidad, y, en tercer lugar, la importancia de rechazar la naturalización de lo humano como compendio único de lo masculino y femenino, dentro de lo cual lo femenino se subsume. La filósofa plantea que el postmodernismo feminista:

Puede exigir que nos opongamos a los retornos fantaseados a la totalidad primigenia de la infancia, a las sociedades anteriores a las clases sociales o a la conciencia 'unitaria', anterior al género, de la especie, que han motivado las epistemologías del punto de vista. Desde esa perspectiva, las reivindicaciones feministas solo son más aceptables y menos deformantes si se basan en la solidaridad entre estas identidades fragmentadas modernas y entre las políticas que crean (Harding, 1996, p. 26).

Este enfoque es una muestra de la disposición de las epistemologías críticas feministas de mantener sus teorías e hipótesis expuestas al continuo examen como parte de la actitud crítica que han adoptado. El ejercicio crítico no puede ejercerse solamente en función de las disciplinas externas al quehacer crítico feminista ya que se estaría incurriendo en el error mismo de las epistemologías tradicionales. La veracidad del conocimiento para las ECF radica en la diversidad de reflexiones y experiencias más que en la unidad del saber.

El postmodernismo feminista origina sus propias tensiones. ¿De qué modo revela las incoherencias, como en el caso de las epistemologías empiristas y del punto de vista, en su discurso original y principal? ¿Podemos permitirnos renunciar al intento de elaborar una 'única descripción feminista y auténtica de la realidad' ante las profundas alianzas entre la ciencia y los proyectos sociales sexistas, clasistas e imperialistas? (Harding, 1996, p. 26). 


\section{Epistemologías Críticas Feministas}

Harding deja claro, que en todos los discursos epistemológicos feministas existen tendencias contradictorias y cada uno posee su propio conjunto de problemas. Pero los problemas y las contradicciones -explica la autora-, no se originan en los discursos feministas, sino que reflejan el desorden presente en las epistemologías y filosofías de la ciencia dominante desde mediados de los años sesenta. También refleja cambios en las configuraciones de género, etnia y clase social, tanto en las categorías como en la realidad.

Harding (1996) resalta este tipo de ambigüedad en la aplicación del método científico, la falta de coherencia entre los resultados que arroja una disciplina, con el mismo método y el carácter inflexible que se le ha otorgado. Dice la filósofa:

Yo sostengo que una ciencia social crítica y reflexiva debe ser el modelo de todas las ciencias y que, si la física presenta unos requisitos especiales para llegar a explicaciones adecuadas, son precisamente eso: especiales (veremos que gran parte de la biología debería conceptuarse ya como ciencia social. Si pensamos en ella como el puente entre $-\mathrm{o}$, desde una perspectiva postmodernista, el crisol en el que se forjan- lo natural y lo social, la naturaleza y la cultura, la biología debe adoptar, con frecuencia, unos tipos de supuestos básicos metafísicos y metodológicos muy alejados de la física y de la química) (p. 40).

La autora aquí defiende el carácter social de la ciencia y los problemas que presenta el método científico cuando se aplica a ciencias diferentes de las naturales. Para esta pensadora no existirían las disciplinas y el saber científico si antes no se hubiese forjado una idea en el pensamiento de la humanidad, si no se hubiese planteado, debatido, y en algunos casos corroborado al interior de las comunidades humanas todo lo que conocemos hoy como técnica, tecnología, ciencia, arte.

En este capítulo se ha realizado un recorrido rápido por los diferentes planteamientos a través de la historia sobre la epistemología. Ha quedado claro que existe gran diversidad de epistemologías que se han elaborado y que han dado pie a una importante ambigüedad a la hora de tener que 


\section{Epistemologías Críticas Feministas}

decidir cuál de ellas se acerca con mayor certeza y cuál es la forma más adecuada de llegar al conocimiento.

Es importante dicha ambigüedad porque nos brinda la oportunidad de continuar indagando el saber por el saber. Harding considera que la búsqueda por el conocimiento siempre está vigente y siempre existe la necesidad de aportar, de cuestionar y de replantear algo. A continuación se van a presentar las limitaciones que las ECF han encontrado en las ciencias, pero también las propuestas que han surgido como alternativas para fortalecer las debilidades que el sesgo androcéntrico ha dejado a su paso por el saber científico que conocemos.

\section{CAPITULO II. ALGUNAS PROPUESTAS DE LAS EPISTEMOLOGÍAS CRÍTICAS FEMINISTAS A LAS LIMITACIONES DE LA CIENCIA TRADICIONAL}

\section{Las limitaciones de la ciencia según las Epistemologías Críticas Feministas (ECF)}

En las epistemologías expuestas anteriormente se muestran ópticas diferentes en que se ha construido el saber científico y cómo este ha afectado todas las dimensiones del ser y del saber humano, de las instituciones y de la historia. Los debates epistemológicos se dan sobre la normatividad que comprende la ciencia, quiénes producen la ciencia, quiénes avalan la veracidad de una disciplina para denominarla ciencia y en qué sentido y condiciones se debe reproducir un conocimiento científico. Como se mencionó en el capítulo anterior, el saber científico no existe independiente de los contextos históricos y de las ideologías, presupuesto asumido en esta investigación.

Así las cosas, este capítulo se centra en profundizar en algunos de los postulados de las ECF, acerca de las limitaciones del saber científico; específicamente: el sesgo falocéntrico, la falsa neutralidad, el utópico universalismo y la ahistoricidad. Estas críticas a la ciencia se desarrollan a partir de tres apartados: la estructura social de la ciencia, las mujeres como objetos de estudio científico; y, la construcción teórica, conceptual y de problemas relevantes en las ciencias. La 


\section{Epistemologías Críticas Feministas}

identificación y el examen de estas limitaciones por parte de los académicos y las académicas feministas pretenden denunciar que el acceso, la creación y la reproducción del saber científico, no está exento de los sistemas socioculturales de género.

Partiendo de esta pretensión, en la segunda parte del capítulo se presentan algunas propuestas de las ECF frente a las limitaciones de la ciencia, para luego reflexionar sobre cómo el sistema educativo formal contribuye a la reproducción de los aspectos androcéntricos de la ciencia y ver las posibilidades de incorporación de las propuestas de las ECF en el contexto de la Educación Primaria y Secundaria, que es el objetivo principal de este trabajo.

En este capítulo también se estudia todo el proceso que han tenido que superar las mujeres para acceder a la educación, ser reconocidas como sujetos de conocimiento, recibir el título profesional y después ejercer su carrera en el campo laboral. Seguidamente se muestra el papel que han jugado los estereotipos para la subalternización de las mujeres en el trabajo, la cultura, la sociedad y la ciencia. Todo esto con el fin de tener claros ciertos aspectos históricos de los feminismos que deben enseñarse en la escuela.

\section{Estructura social de las ciencias}

En este apartado se profundiza uno de los aspectos mencionados en el capítulo anterior acerca de cómo la estructura social de la ciencia reproduce las jerarquías de género que excluyen y subalternizan a las mujeres en la ciencia. Esta afirmación se sostiene siguiendo especialmente el texto Ciencia y feminismo de Sandra Harding, y el texto La igualdad también se aprende: cuestión de coeducación de María Elena Simón Rodríguez. Harding (1996) dice que:

La vida social generizada se produce a través de tres procesos distintos: es el resultado de asignar metáforas dualistas de género a diversas dicotomías percibidas que no suelen tener mucho que ver con las diferencias de sexo; es consecuencia de recurrir a estos dualismos de género para organizar la actividad social, de dividir las actividades sociales necesarias entre diferentes grupos de seres humanos; es una forma de identidad individual, 


\section{Epistemologías Críticas Feministas}

socialmente construida, que solo se correlaciona de modo imperfecto con la 'realidad' o con la percepción de las diferencias de sexo (p.17).

Para la autora estos tres aspectos también se reproducen en la ciencia y por eso acuña la expresión simbolismo de género, es decir que en el ejercicio científico y en la organización social del trabajo, se han marcado estereotipos que determinan la participación y aceptación de uno y otro género, en el que también intervienen la estructura de género y el género individual. Esta caracterización, ha dado origen a dos cuestiones principalmente: El acceso de las mujeres a la educación y las posiciones subalternas de las mujeres en las instituciones así como en el trabajo científico.

La en favor de la educación fue una de las primeras reclamaciones invocadas por las mujeres, por lo menos de las mujeres de clase media en Europa occidental a finales del siglo XVIII como medio para incorporarse al espacio público y así lograr independencia y autonomía personal.

El acceso a la formación académica lleva implícitos dos grandes hitos en la historia de las mujeres; por un lado, la posibilidad de acceso a trabajos de mayor cualificación que los que tradicionalmente ellas realizaban en la industria o en la agricultura, pasando a ocupar trabajos de «cuello blanco», y el segundo gran hito será el reconocimiento social de las potencialidades intelectuales de las mujeres, al mismo tiempo que se reforzaba su autoreconocimiento como individuos de pleno derecho.

Al analizar los pormenores y las luchas que han enfrentado los feminismos para que las mujeres sean reconocidas como sujetos de aprendizaje, se descubren las limitaciones sociales, culturales, políticas y religiosas que se han impuesto en contra de la formación académica de las mujeres, la titulación, la profesionalización y la contratación.

Harding, en el capítulo uno, resalta las alusiones que los estudios sobre la equidad han realizado, frente a los procesos que, por un lado, se presentan como exigencias de las feministas frente al derecho de ser incorporadas a las instituciones educativas; y, por otro lado, la denuncia sobre las restricciones que esta iniciativa ha motivado en algunos sectores académicos, según ella: 


\section{Epistemologías Críticas Feministas}

Antes que nada, los estudios sobre la equidad han documentado la masiva oposición histórica a que las mujeres tuvieran a su disposición una educación, títulos y trabajos semejantes a los de los hombres de capacidades similares; así mismo, han identificado los mecanismos psicológicos y sociales mediante los que se mantiene la discriminación de manera informal, aunque se hayan eliminado los obstáculos formales (Harding, 1996, p. 20).

La resistencia frente a la educación profesional de las mujeres -resalta la autora- se ha perpetuado a través de los siglos, ligada a las interpretaciones deformadas que la biología y la cultura han naturalizado en detrimento de las aptitudes de las mujeres. A finales del siglo XIX e inicios del siglo XX, en Norteamérica las lecciones del núcleo familiar y de la iglesia católica eran destinadas exclusivamente a que las mujeres realizarán quehaceres domésticos y atendieran a su esposo y a sus hijos. La formación en culinaria, buenos modales, costura y música, los impartía la madre como proceso de adiestramiento para el hogar. María Elena Simón Rodríguez (2011), expone el proceso histórico español que caracteriza la lucha que han enfrentado las mujeres para mejorar las condiciones de vida a las que se han visto expuestas en el transcurso de la historia, según esto:

La educación de las mujeres padeció secularmente el defecto de la privación. Las sociedades antiguas, así como las medievales y las modernas, relegaron la educación de las niñas al ámbito familiar, donde las madres fueron las encargadas de transmitir, aleccionar, domar si era necesario y enseñar todo aquello relacionado con el único oficio que se proveía para todas ellas: el de madreesposa ${ }^{7}$ (p. 23).

El rol social de las mujeres - como lo enuncia Simón- estaba determinado por la educación que se ofrecía a las niñas desde el hogar, determinadas estas últimas por las disposiciones y enseñanzas de la iglesia católica. Este tipo de restricciones que se les impuso a las mujeres, se reforzó cuando se conformaron las primeras universidades europeas -comenta Simón (2011)-:

\footnotetext{
${ }^{7}$ Este concepto así expresado se retoma de Marcela Lagarde, (1990). Los encierros de las mujeres: Madreesposa, monjas, putas, presas y locas. México: Unam.
} 


\section{Epistemologías Críticas Feministas}

Se crearon entre los siglos XII y XIII e impidieron la entrada a las jóvenes, con lo que se les negó el acceso al conocimiento oficial, relegando sus saberes a la categoría de la magia o mejor dicho de la brujería, controlada en un momento dado por la inquisición (p. 24).

Los saberes de las mujeres se quedaron en los márgenes y no pasaron al llamado canon académico. No se escribieron y solo se transmitieron por linaje oral y presencial de unas a otras. A las médicas y farmacólogas se les llamó curanderas y en el mejor de los casos, sanadoras. En ese mismo orden, continuando con Simón:

Desde la mitad del siglo XIX, empezó a tomar cuerpo la vindicación feminista por la educación para las niñas, desde la Primaria hasta la Superior. En España, voces y personas destacadas trabajaron para que así fuera -como fue el caso de Emilia Pardo Bazán-; o con su propia experiencia y acción de vida, como Concepción Arenal, que logró colarse en las aulas de la Facultad de Derecho de Madrid, vestida como un alumno (Simón, 2009, p. 24).

Acciones como las que expone Simón permiten crear un panorama claro sobre la imposibilidad y el menosprecio que se ha venido implementando en la ciencia, la cultura y la educación frente a la incorporación de las mujeres en el ejercicio profesional. En el siglo XIX en España-como ya se mencionó-, se brinda el acceso restringido de las niñas a la escuela, con cursos muy elementales, y sin mezclarse con los niños, ya que no podían recibir enseñanzas de maestros hombres. A falta de maestras se habilitó de forma empírica a las mujeres que por la experiencia y práctica realizada, hubiesen aprendido en el seno de la familia algunas letras, números y sobre todo, las labores propias de su sexo para que impartieran clases a las niñas de algunos sectores privilegiados de la sociedad.

De forma precaria se fueron extendiendo geográficamente en España las escuelas de las niñas, junto con los colegios religiosos de monjas, donde se educaba a las hijas de las clases medias y altas, pero negándoles el acceso al bachillerato, «extremo que les impedía el futuro acceso a la universidad, cosa que no ocurría jamás con sus hermanos varones, sino muy al contrario: ellos 


\section{Epistemologías Críticas Feministas}

estaban llamados a dirigir los campos de la actividad humana, -masculina- debemos añadir» (Simón, 2009, p. 25).

En cuanto a la Enseñanza Media, no existían instituciones para formar a las mujeres, pues aún no se habían creado las instituciones femeninas, constriñendo la posibilidad de que las mujeres pudiesen llegar a estudios superiores. Sin embargo, la solución a esta necesidad se fue resolviendo con la preparación extraacadémica y los exámenes libres que facultaban para el paso a los distintos grados a un número reducido de chicas: de familias cultas, económicamente solventes, urbanas y dispuestas a invertir en la educación y titulación de sus hijas. No obstante comenta Simón (2011):

Las candidatas a estudiantes tuvieron que alegar todo tipo de excelencias y pasar por pruebas de acceso especialmente diseñadas para ellas y por tribunales que las examinaban por todas partes: no solo por su solvencia intelectual y científica, sino por sus cualidades, actitudes o presentación. A algunas les dejaron inscribirse con muchas condiciones pero también les impidieron realizar el último examen, llamado 'de grado', que daba acceso al título correspondiente. De este periodo quedan documentos escritos y gráficos que dan buena cuenta de la carrera de obstáculos que significó para las universitarias acabar sus estudios con éxito. Más tarde se les impidió doctorarse y colegiarse como profesionales, para que pese a sus flamantes títulos no pudiesen ejercer (p. 25).

Los requisitos para el ingreso de una mujer a la educación superior eran muy rigurosos -como se puede observar en líneas citadas anteriormente-, esta es una de las razones fundamentales afirma Simón- por lo que en España el número de mujeres en las aulas de clase de educación superior era reducido. Lo mismo sucedía en Norteamérica y en otros países del mundo según las investigaciones de Harding. También hay que hacer énfasis en la clasificación por género de algunas carreras profesionales, con el argumento de que las mujeres carecían de capacidades y aptitudes, que les impedía ejercer ciertas prácticas profesionales.

En la segunda mitad del siglo XIX, aparecen escuelas que hoy llamaríamos de formación profesional, incluida en este concepto las Escuelas Normales de Maestras; de comercio; de 
correos y telégrafos; de enfermeras; y de mecanógrafas y taquígrafas. Estas son hasta hoy y no por casualidad profesiones y oficios femeninos y «femenizados». Diana Crucelly González Rey, en el artículo titulado La educación de las mujeres en Colombia a finales del siglo XIX: Santander y el proyecto de educativo de la regeneración, comenta acerca del debate que se desarrolló en Europa sobre el ejercicio de la razón durante el siglo XVIII, en especial en torno al papel de las mujeres, la ilustración y su educación, introduciendo por primera vez la noción de igualdad en la querella entre sexos.

Según la autora, pensadores como Poullain de la Barre realizaron aportes transformadores en el Viejo Mundo al afirmar «que el espíritu no tiene sexo, asegurando que la razón que define la pertenencia humana, corresponde por igual a hombres y mujeres» (Poullain como se citó en Godineau, 1995, p. 399). El debate acerca de la razón en las mujeres implicó largas discusiones en donde se llegó a afirmar que ellas no tenían una razón igual a la de los hombres; la razón de las mujeres en este período se determinó bajo las funciones sexuales y reproductivas de los géneros, porque "el útero", órgano femenino por excelencia, determinaba a las mujeres, definiéndola por su sexo y no por su razón, como en el hombre.

En Colombia, como en España y en otros países occidentales, no se configuraba la idea de formar académicamente a las mujeres. Los avances frente a este tema, facilitó gradualmente continuas incursiones de los movimientos feministas que exigían la incorporación de las mujeres en las decisiones políticas y públicas. Según González (2015):

Con la reforma educativa impulsada por el gobierno de la Unión en 1870 en los Estados Unidos de Colombia se originó un proceso de formación de las maestras, materializado con la apertura de escuelas normales para la formación de maestros en todo el país. (p. 244245).

La realidad del proceso educativo para las mujeres colombianas difiere de otros contextos como el europeo; sin embargo, en el país, algunos académicos influenciaron la renovación de una forma renovada de la educación acorde con los principios de la civilización europea del siglo XIX. Uno de los casos más conocidos es el de José Celestino Mutis, quien en más de una ocasión 


\section{Epistemologías Críticas Feministas}

denunció el estado de la educación en la Nueva Granada, «inculpando a las órdenes religiosas por impedir el desarrollo de una verdadera universidad» (Díaz, 2005, p. 120).

Uno de los antecedentes de la educación femenina en Colombia -comenta Pilar Foz y Foz-, lo representó el Colegio de Enseñanza de Niñas de doña Clemencia de Caycedo en Bogotá, quien «al tomar conciencia de la problemática femenina en lo referente a la educación, se incorporó a una de las manifestaciones más claras y llenas de futuro de la ilustración» (Foz, 1997, p. 265).

Para inicios del siglo XIX se recuerda el caso de la madre María Petronila Cuellar, quien no solo da cierta continuidad al proyecto de Clemencia de Caycedo, sino que plasma «a través del ejercicio de la escritura, previo consentimiento de su confesor, el diseño de un orden encargado de moldear la educación femenina por largos años en una escritura conventual apegada a los valores religiosos donde la religiosa se desahogaba» (García, 1995, p. 78-79).

En este período la enseñanza de las mujeres, así hubiese sido de tipo religioso y conventual, resultó ser toda una novedad y hasta una transgresión. María Petronila abre por primera vez la posibilidad de que las mujeres educadas en el Convento de la Enseñanza vivieran de su trabajo. Esas lecciones, esos ejercicios, esas conversaciones espirituales, esas tareas y labores, le proporcionarían a la estudiante con qué ganar algún día el sustento.

En la primera década del siglo XX, en España se alcanza un hito histórico: «en 1910, por fin se permite la matrícula universitaria a cuantas aspirantes lo solicitaron y, por tanto, se accede a que se matriculen con las mismas condiciones que los estudiantes varones» (Simón, 2009, p. 26). En Colombia la educación superior para las mujeres, comenzó como un derecho por ley, se convirtió en uno de los logros de la modernidad del país.

La profesora María Imelda Ramírez redactó en 1935 un texto, en él mostraba cómo se había dado en Colombia el ingreso de las mujeres a la educación superior. Según la profesora

En Colombia, el 10 de diciembre del año 1934 se presentó al Congreso de la República un proyecto de ley para que las mujeres pudieran ingresar a la universidad en igualdad de 
condiciones que los hombres. Esto suscitó una gran controversia como todo lo que tenía que ver con los derechos de las mujeres. Alfonso López Pumarejo abrió sus puertas por primera vez en Colombia a las jóvenes que aspiraban cursar una carrera diferente al proyecto matrimonial y familiar al cual habían estado adscritas de manera exclusiva. Gerda Westendorp fue admitida en 1935 a la carrera de medicina e inició clases probablemente el primero de febrero. Pero Gabriela Peláez, que ingresó en 1936 a estudiar derecho, se convertiría en la primera abogada colombiana (Ramírez, 1935, p. 1).

Además de estos hechos la profesora remite a otros acontecimientos, que fueron ampliando la presencia de las mujeres en la educación superior y en la vida pública. María Carulla fundó en 1936 la primera escuela de trabajo social adscrita a la Universidad del Rosario. La apertura que tuvieron las facultades de ciencias sociales frente al ingreso de las jóvenes, contribuyó en la lucha de las mujeres por alcanzar el reconocimiento de la ciudadanía plena y la oportunidad de contar con otra mirada calificada sobre la vida, los problemas sociales, el pasado, las artes, las ciencias. Se empezaron a despejar las dudas sobre la inferioridad intelectual de las mujeres, al demostrar las primeras universitarias que eran competentes en sus trabajos académicos, creativos y disciplinados (Ramírez, 1935).

Cada logro en la lucha por la incorporación de las mujeres en la vida estudiantil y laboralprofesional ha significado un logro en la búsqueda de la equidad y la superación de los estigmas que se han construido en contra de la participación pública de las mujeres. Cada reaccionaria feminista se ha tenido que convencer de las habilidades que posee y reconocer el velo que se había tendido para negar y cegar las aspiraciones de algunas mujeres por alcanzar la igualdad de derechos, el reconocimiento de la diferencia y de las potencialidades cognitivas que toda mujer posee.

Esta reflexión permite alinearnos con Harding acerca de su tesis de que, si bien estos cambios han significado importantes logros, como el acceso a la educación y el aumento del número de mujeres profesionales dedicadas a la ciencia, la división del trabajo en la ciencia ha mantenido a las mujeres en roles inferiores a los de los hombres. 


\section{Epistemologías Críticas Feministas}

En el capítulo anterior se mostraban algunos de los argumentos de Harding que evidencian el rol inferior de las mujeres en la ciencia y la educación, en este capítulo se han querido precisar algunos de ellos. La autora identifica como tipos de segregación, el establecimiento de estereotipos de feminización; ella dice que las mujeres en la familia fueron educadas para asumir el rol de «madreesposas», seguidamente a este ejercicio familiar, se naturaliza esta idea en la cultura, y por último se reflejan estos estereotipos en la educación y el campo laboral. Esto significó asumir el precio el precio - como lo muestra Rossiter- «de aceptar un modelo de trabajo segregado y de reconocimiento insuficiente del que muchas mujeres no pudieron escapar, aunque lo intentasen» (Rossiter como se citó en Harding, 2006, p. 54). En consecuencia -dice Rossiter-:

(...) aunque, en 1920, las mujeres podían decir que tenían 'abiertas las puertas' de la ciencia, estaba muy claro que se limitaban a ocupar unos puestos que no pasaban del vestíbulo'. La segregación vertical y la horizontal se combinaban para garantizar el mantenimiento de esta situación (Harding, 2006, p. 56).

El simbolismo de género es una de las razones por las cuales, en la estructura social de las ciencias, no es cierto que haya democracia. Como lo afirma Harding en el texto Ciencia y feminismo, estos estereotipos superaron la idea inicial de las mujeres que creyeron que con solo acceder a la educación y a la ciencia iban a rescatar un puesto significativo en el ejercicio de las mismas; lo que ha mostrado la historia es que esto que no pasa. Los estereotipos sociales de género han mostrado que las mujeres que se caracterizan por sus conductas suaves, delicadas, emocionales, no competitivas y asistenciales, no encajan con los estereotipos sociales de la ciencia, como lo caracteriza Harding, dura, rigurosa, racional, impersonal, competitiva y no emocional.

Otro de los argumentos que resalta Harding es que la identidad masculina depende de la inferiorización de la identidad femenina. La hipótesis dice que los hombres construyen parte de su subjetividad solo en función de cómo se construye la subjetividad femenina; y por eso los hombres sintieron - dice Harding- que la feminización de la ciencia es una amenaza para el ejercicio científico de los hombres. 
Epistemologías Críticas Feministas

\section{Objetos de Estudio}

Una segunda crítica a la ciencia que se hace desde las ECF es que el lugar específico de las mujeres en la ciencia se ha caracterizado no por el rol de sujetos que investigan sino por el rol de objetos de investigación. La ciencia, según Diana Maffia, se ha encargado de proporcionar descripciones de la naturaleza femenina que ubican a las mujeres en un lugar diferenciado y jerárquicamente inferior al hombre. El método, denuncia la autora, consiste siempre en: 1) señalar diferencias biológicas y psicológicas naturales e inevitables entre los hombres y mujeres; 2) jerarquizar esas diferencias de modo tal que las características femeninas son siempre e inescapablemente inferiores a las masculinas; y 3) justificar en tal inferioridad biológica el status social de las mujeres (Maffia, 2007, p. 70).

Lucía del Moral Espín, en el texto En transición. La epistemología y filosofía feminista de la ciencia ante los retos de un contexto de crisis multidimensional, plantea que es una tendencia que «se traduce en la creación de una alteridad, de un 'Otro' como objeto de conocimiento desprovisto de saber y cultura, espejo de la Modernidad occidental y de sus elites dominantes masculinizadas» (Harding, 2004, p. 2; Santos, 2005, p. 10; Del Moral, 2012, p. 52). Este 'Otro', que Harding llama fearfull specters ${ }^{8}$, responderá a las relaciones de dominación y subalternidad ya existentes: sexo, etnia, clase y asume las formas como de oriente, o del salvaje, o de la naturaleza o, de las mujeres. Esta forma de ver al otro se funda según Del Moral en dos dicotomías:

Por una parte la dicotomía 'saber moderno' y 'saber tradicional' basada en la idea de que el conocimiento tradicional es práctico, colectivo, fuertemente implantado en lo local y hasta exótico. Por otra, la dicotomía entre conocimiento técnico o especializado o científico y conocimiento lego o tácito, que entiende el primero como imperativo de rigor, de eficacia o de racionalidad. Estas dicotomías, a su vez, se asientan sobre dos narrativas que se apoyan mutuamente: el excepcionalismo y el triunfalismo. La primera plantea que entre los distintos tipos de conocimiento humano, solo las ciencias occidentales atrapan la realidad

\footnotetext{
${ }^{8}$ Sujeto pasivo y medianamente visible que borrosamente se deja percibir
} 
en sus propios términos y logran 'evitar la tendencia humana universal a proyectar supuestos culturales, miedos y deseos en la naturaleza' (Harding, 2008: 4) y que, por lo tanto, solo existe una Modernidad, la occidental. La segunda, la triunfalista, considera que la historia de la ciencia es una narrativa de logros, sin puntos negativos ya que se debe diferenciar entre la neutralidad intrínseca de una ciencia con vocación benigna y ciertas aplicaciones perversas que históricamente se han hecho de ella (Del Moral, 2012, p 52).

Entendemos, de acuerdo con lo que plantea Del Moral, que las mujeres han sido incapacitadas por las políticas públicas, por la sociedad y por la ciencia para ser sujeto de conocimiento. Han dejado a las mujeres expuestas como objetos de estudio, como el género diferente y confuso que nadie logra comprender, es lo «otro», lo desconocido, lo «alter humano» que hay que indagar, que se debe conocer porque no es hombre. Justa Montero (2006), plantea que existen «importantes fisuras en una de las dicotomías más fuertemente desarrolladas por la modernidad: La que separa lo privado y lo público. «Lo público donde concurre lo que se considera de interés general, y lo privado entendido como el ámbito de lo personal» (p. 172). Las mujeres están ubicadas en lo privado en cuanto no se le daba participación pública, por ejemplo, se le restringía el acceso al voto, se le impedía el acceso a ejercer labores donde implicara aplicar la autoridad, trabajos de destreza y fuerza eran considerados fuera de su alcance, -como ya se ha mencionado- el acceso a la educación superior estaba orientado y limitado de acuerdo con la cultura de la mujer madre-esposa.

En estas dicotomías, las mujeres ocuparían de acuerdo con el saber tradicional, el conocimiento lego y el ámbito de lo privado. Lo que las deja fuera de los parámetros del mundo de la ciencia y no participan más que como objetos de estudio. Esta idea prevalece en la actualidad debido a los estereotipos de feminización que se siguen reproduciendo en la educación y la cultura.

Por todo lo anterior, las ECF se han preocupado por desvelar el conocimiento que la ciencia ha producido sobre las mujeres, su naturaleza, sus características, y sobre cómo este conocimiento ha impedido que sean sujetos que conocen, específicamente sujetos que pueden producir conocimiento científico. Esto se ha hecho a partir de dos proyectos: humanizar las ciencias e incorporar nombres de mujeres destacadas en las ciencias. 


\section{Epistemologías Críticas Feministas}

Las cualidades de sensibilidad y emocionalidad, independientemente del género de quienes hacen la ciencia, permiten una visión diferenciada y diferenciadora de las ciencias que actualmente se ponen en práctica para abrir la posibilidad de humanizarlas, aterrizándolas a los contextos y a las necesidades sociales que cada espacio y tiempo generan. Las ECF no intenta negar estas cualidades y características atribuidas a las mujeres para que estas puedan volverse científicas. Esto sería aceptar que para hacer ciencia es fundamental aplicar el desapasionamiento en el ejercicio investigativo; pero y ya hemos visto que no importan las características atribuidas a los géneros, no importa si se es sensible o frío, dulce o insensible, empático o egoísta, pues la práctica científica siempre lleva las marcas del pensamiento de sus creadores colectivos o individuales y, a su vez, los creadores están marcados de forma característica por su género, clase social, etnia y cultura, como bien lo afirma Harding.

Otros proyectos feministas se han centrado en mostrar que las mujeres han participado en la ciencia, incorporando nombres de mujeres notables como los de la científica polaca y premio Nobel de Física en 1903 y de Química en 1911 Marie Curie; la primatologa inglesa Valerie Jane Morris-Goodall, quien ha realizado profundas investigaciones científicas sobre el comportamiento, uso de herramientas y los modos de vida de los chimpancés; la Francesa Marie Shophie Germain quien realizó grandes aportes a la teoría de la elasticidad y los números; la Alemana Amalie Emmy Noether quien podría, como Einstein la consideró, la mujer más importante en la historia de las matemáticas, especialmente en la física teórica y el álgebra abstracta; la premio Nobel por «su teoría de los genes saltarines», la Norteamericana Barbara McClintok. Otros proyectos muestran la importancia de las mujeres en la historia del conocimiento como el texto de Gilles Ménage Historia de las mujeres filósofas.

Esto es valioso, pero como menciona Harding, está presente la dificultad de que aún son vistos por la ciencia como trabajos subalternos que necesariamente han requerido el aval de los hombres para su realización. Aunque el proyecto de visibilizar los nombres de mujeres notables ha sido importante para la construcción de una ciencia más equitativa y menos androcéntrica, esto tiene la limitación de no reflejar la vida de todas las mujeres y de no ser una crítica contundente acerca de cómo la ciencia reproduce el modelo sexista. Este modelo no solo se 


\section{Epistemologías Críticas Feministas}

reproduce por la negación de mujeres que se han destacado en el campo; sino, como ya dijimos, por la división del trabajo científico que dificulta que las mujeres sobresalgan. Adicionalmente y aún más importante, el sexismo en la ciencia se reproduce a través de los conceptos, los marcos teóricos y los problemas que se consideran relevantes para la investigación científica.

El siguiente apartado muestra la desmedida relevancia que se le ha otorgado a lo masculino y a la influencia del sesgo androcéntrico en la elaboración de los conceptos, marcos teóricos y problemas científicos. La estructura de la historia científica por sí misma muestra la tendencia de dar un valor excesivo a la figura distorsionada de un modelo de mundo que se articula de manera conveniente al mundo masculino, desechando intencionalmente la participación de lo femenino o natural, como alternativa y contingente para todos los estudios realizados y por realizar.

\section{Conceptos, marcos teóricos y problemas científicos}

Una tercera crítica, estrechamente ligada a la anterior, es la falsa mitologización de la neutralidad y universalidad de la ciencia. Como vimos, las ciencias naturales y humanas han producido un saber sobre las mujeres que reproduce su lugar de subordinación; y las ubica como objetos y no como sujetos de conocimiento. Una de las explicaciones de las ECF, es la que da Harding acerca de que los conceptos, los marcos teóricos y los problemas que plantea la ciencia también llevan la marca del simbolismo de género.

Cada elaboración teórica y científica en el ámbito de las ciencias posee de manera implícita la idea de que todo aquello que es masculino posee rigurosidad, por el contrario, todo aquello que posee contingencia y ambigüedad es de carácter femenino. Para este apartado se va a retomar el capítulo IV del texto Ciencia y Feminismo, en donde la filósofa Sandra Harding expone los análisis de María Millman y Rosabeth Kanter. De igual forma, se va a compilar el conjunto de las primeras críticas que se identificaron como problema en los años setenta y que siguen constituyendo áreas fundamentales de las preocupaciones feministas. Millman y Kanter, en

primer lugar, señalan que se han pasado por alto importantes áreas de investigación social a causa del uso de ciertos modelos convencionales de definición de campos 


\section{Epistemologías Críticas Feministas}

Por ejemplo, la función de la emoción en la vida social y en la estructura social tiende a hacerse invisible en los análisis sociológicos que se centran exclusivamente en la función de la racionalidad weberiana [...] En ningún caso se considera significativa la conciencia del sentimiento ni de la emoción entre las razones o causas de las acciones y creencias de las personas ni como elemento de la estructura social y, sin embargo, esa conciencia de los sentimientos parece un elemento evidente e importante de nuestras propias creencias y conductas y de las de los demás. (Millman y Kanter citadas por Harding, 1996, p. 76).

Las autoras consideran que el hecho de negar el carácter que tiene el «sentimiento» en todas las dimensiones humanas, no implica la inexistencia del mismo en todas las acciones humanas. Sin embargo, la atribución netamente femenina que se ha hecho de esta categoría humana y que se ha implementado en cada cultura desestima el valor axiológico de la misma, por lo que no se tiene en cuenta como un criterio válido para la epistemología. Retomando a Millman y Kanter:

Por una parte, los estereotipos de género suponen que la motivación por sentimientos y emociones conscientes corresponde en exclusiva a las mujeres, mientras que los hombres estarían motivados por el cálculo instrumental u otras consideraciones 'raciales'. Por otra parte, la ciencia social asume que las actividades y creencias de los hombres sobre todo, crean la estructura social (Millman y Kanter, 1996, p. 76 - 77).

La feminización de los sentimientos y las emociones ha blindado la posibilidad de que los hombres se puedan identificar de alguna manera con este tipo de vivencias humanas y por esta razón no se tienen en cuenta, además se les categoriza como funciones inútiles del ser humano y como distractores para el ejercicio serio, riguroso e imparcial de las prácticas científicas.

En segundo lugar - continuando con Millman y Kanter- consideran que la sociología se ha centrado en los personajes de la situación pública, oficial, visible, espectacular o todos ellos; sin embargo, las esferas no oficiales, de apoyo, menos espectaculares, privadas e invisibles de la vida y de la organización social, pueden tener la misma importancia. Estas restricciones del campo de acción social pueden deformar nuestra comprensión de la vida social. 


\section{Epistemologías Críticas Feministas}

Por ejemplo, tienden a dejar en la sombra las formas de conseguir las mujeres el poder informal. Ocultan el sistema informal de patrocinio y mecenazgo de los hombres, que garantiza un envidiable desarrollo de carrera para los profesionales varones y, al mismo tiempo, aísla a las empleadas, burlando, por tanto, los objetivos declarados de los programas de acción afirmativa (Millman y Kanter, 1996, p. 77).

Bajo estos criterios, las pensadoras denuncian el proceso de invisibilización que se practica en contra de las mujeres que han alcanzado la categoría de genios en la historia del arte, la literatura, la política y las ciencias. Las superestructuras masculinas de las relaciones sociales subsumen cualquier intento que las mujeres realizan por demostrar las aptitudes que poseen, ya que los hombres aparecen siempre como los creadores de la estructura social.

En tercer lugar, continuando con los comentarios de Harding sobre Millman y Kanter, la sociología asume con frecuencia la existencia de una 'sociedad única' «con respecto a hombres y mujeres, en la que pueden hacerse generalizaciones sobre todos los participantes, aunque, en realidad, los hombres y las mujeres habiten mundos sociales diferentes sin que se tenga en cuenta esa diferencia» (Millman y Kanter Citadas por Harding, 1996, p. 77).

El concepto «Hombre» se ha utilizado por siglos para designar a los hombres y las mujeres de manera unívoca, siempre que se hacía referencia sobre este concepto en los libros de texto y los libros especializados, se sobreentendía que las mujeres estaban incluidas. Sin embargo, este es un grave error de la sociología:

El supuesto básico corriente de que una determinada estructura social o tipo de conducta es funcional para los agentes de la sociedad suele ignorar el desajuste entre la consciencia, los deseos y las necesidades de las mujeres y las funciones que se les asignen» (Millman y Kanter como se citó en Harding, 1996, p. 77-78).

La diferencia que existe entre los hombres y las mujeres es lo que ha abierto la posibilidad de estructurar las diversas críticas que han denunciado las deficiencias metodológicas, teóricas y en 


\section{Epistemologías Críticas Feministas}

algunas ocasiones, prácticas, que la filosofía de las ciencias ha estructurado en torno a los grandes paradigmas científicos (universalidad, neutralidad, ahistoricidad, objetividad, verdad).

En cuarto lugar y asumiendo las diferencias que tiene Harding frente a Millman y Kanter sobre la forma de concebir el sexo y el género, Harding reconoce al igual que Simone de Beauvoir que «No se nace mujer: se llega a serlo» (Beauvoir, 2005, p. 109). Según Harding «las interpretaciones sociales de la sexualidad y del género son las responsables de la asignación de funciones distintas en la vida social a mujeres y hombres» (Harding, 1996, p. 79). Al igual que las mujeres, los hombres tampoco «nacen, sino se hacen», pero figurando de forma imprecisa como el perfil de la "humanidad". No obstante, las necesidades y deseos masculinos no han sido los únicos elementos configuradores de la historia, también las actividades socialmente construidas de las mujeres. Millman y Kanter dicen:

Cuando los sociólogos (o los hombres, en general) observan una reunión de un consejo de administración y ven solo a hombres, piensan que están observando un mundo sexualmente neutro o «asexuado» por «agenerizado», veremos que el problema al que se refieren estas críticas es que se supone que el género es algo que solo atañe a las mujeres, mientras que los hombres son los portadores de la cultura (Millman y Kanter como se citó en Harding, 1996, p. 80).

En quinto lugar, Millman y Kanter consideran que ciertas metodologías (con frecuencia cuantitativas) y situaciones de investigación (casos en los que los científicos sociales varones estudian mundos en los que están involucradas las mujeres) pueden impedir sistemáticamente la manifestación de determinados tipos de información, aunque esta información no develada sea la más importante para explicar el fenómeno sometido a estudio. Las feministas no inician -dice Harding- la crítica de la preferencia excesiva por las medidas cuantitativas. Las autoras consideran que «la novedad que presentan las críticas feministas consiste en la sospecha, antes mencionada, de que la preferencia por el trabajo con variables en vez de personas, 'puede asociarse con un estilo masculino de control y manipulación exagerado hasta la incomodidad (Millman y Kanter como se citó en Harding, 1996, p. 80). 


\section{Epistemologías Críticas Feministas}

Los cinco aspectos señalados en las críticas feministas no constituyen -dice Harding- una relación completa de las diversas formas de presencia generalizada del característico sesgo masculino de las ciencias sociales. No obstante, este señalamiento es suficiente para reconocer el carácter autocrítico de las críticas feministas en tanto que «cuestionan con severidad las pretensiones de neutralidad con respecto a los valores, objetividad y desapasionamiento de las ciencias» (Harding, 1996, p. 81). La autora Pilar Colás Bravo (2004) en el artículo Investigación educativa y crítica feminista, dice que:

El eje que articula las críticas feministas a la ciencia tradicional es el sesgo androcéntrico de la investigación. Las prácticas científicas convencionales contienen un sesgo androcéntrico evidente, tanto en los conceptos y categorías que utilizan en la indagación científica como en los marcos teóricos en los que se inscriben (Sánchez, 1999; Haraway, 1995; Harding, 1995; Fox 1991; citado por Colás, 2004, p. 3).

La autora resalta el elemento fundamental objeto de casi todas las críticas feministas: el sesgo androcéntrico; y es que quienes están realizando las ciencias, no son neutrales a la hora de exponer sus teorías y prácticas. Todos los conceptos, categorías y marcos teóricos enfatizan siempre en la supremacía de lo masculino frente a lo femenino.

\section{Propuestas de las epistemologías críticas feministas para contrarrestar las limitaciones de la filosofía de la ciencia y de la ciencia no crítica.}

\section{Acceso y participación a la educación y al trabajo científico}

Existe en la actualidad, como consecuencia de las luchas sociales libradas, mayor flexibilidad y acceso a la educación universitaria gradual y posgradual así como políticas públicas que respaldan el quehacer científico de las mujeres. Sin embargo, aún no se ha logrado materializar la idea de que los hombres y las mujeres pueden estudiar las mismas disciplinas y ocupar los mismos cargos, las mujeres tienen dificultades para asumir puestos de gerencia, a nivel mundial el número de mujeres presidentes de corporaciones y científicas que son reconocidas es reducido. 
La filósofa Argentina Diana Maffia, plantea la necesidad de una reconstrucción feminista de la ciencia, como reacción a los sesgos que el género imprime a la estructura social de la ciencia:

Desocultar - sería la tarea-, quitar el velo que esconde el sexo (masculino) de la ciencia. Precisamente este es el mérito principal de Londa Schiebinger (1993) describir cómo los padres de la ciencia moderna incorporaron sus prejuicios (no solo de género, sino también de clase y raza) en sus investigaciones sobre la ciencia y la historia natural; explorar el modo en que la raza, el género y la clase han dado forma a las clasificaciones y descripciones científicas no solo acerca de humanos sino también de plantas y animales; mostrar cómo los científicos, como miembros privilegiados de la sociedad, construyen imágenes y explicaciones de la naturaleza que refuerzan sus propios lugares y valores culturales (Maffia, 2007, p. 83).

Esto quiere decir que los científicos varones refuerzan con sus explicaciones el lugar que deben ocupar las mujeres en la estructura social de la ciencia. Es decir, que en la división social del trabajo científico también se reproduce la división social del trabajo basado en estereotipos de género. Siguiendo a Maffia, la propuesta de las ECF consiste en evidenciar cómo las imágenes de la sociedad, incluyen los lugares que deben ocupar los hombres y las mujeres para mostrar que el quehacer científico no es ajeno a esa imagen.

En las disciplinas denominadas «ciencias duras», las mujeres están aún menos representadas, estos campos siguen estando en manos de varones y la comunidad científica sigue sin tener en cuenta la importancia de la presencia de las mujeres y de las apreciaciones de las teorías de género en campos como la física, la química y la biología. Algunas pensadoras como Fox Keller, Bárbara MClintock y Donna Haraway, consideran que las mujeres aún requieren mayor presencia en estas disciplinas ya que ellas al denunciar la interpretación androcéntrica propician cambios en la manera de concebir los problemas, las soluciones y los temas relevantes en estas disciplinas, ampliando la perspectiva de mundo que se tiene.

Podríamos afirmar que la ciencia velada por el sesgo androcéntrico es «mala ciencia» (Harding, 1996), ya que el conocimiento que se obtiene está parcializado, pues excluye a la mitad de la 
población (las mujeres) y reconoce el porcentaje mínimo de hombres que están en un estado favorable (economía, prestigio.), porque los que se encuentran en un nivel económico y académico bajo tampoco son reconocidos. En palabras de Pérez (1998): «la producción de conocimiento válido y relevante se concibe como un proceso de construcción de nuevos significados y representaciones a partir del contraste de las interpretaciones que los diferentes sujetos participantes ofrecen de la situación en la que viven» (p. 61).

Ana Constanza como se citó en Boscán (2011) «sostiene que el feminismo ha puesto en evidencia y denunciado la prevalencia histórica y aún vigente del patriarcado, el cual se manifiesta en el predominio de la racionalidad y las epistemes masculinas» (p. 174). La crítica feminista - continúa Boscán- «se ha constituido como una práctica desde una mirada intrusiva y analítica, que cuestiona y busca la superación del patriarcado, de su ideología y de su forma de pensar, analizar y explicar el mundo» (p. 174). Así, desde el punto de vista epistemológico:

La crítica feminista busca superar el desprecio de la subjetividad -sobre todo, la del sujeto femenino- impuesto por la investigación científica tradicional. En este sentido, devela la falsa objetividad perseguida por una ciencia dirigida y controlada por hombres que han pretendido desarrollar discursos y prácticas fuera del contexto sociopolítico y de género, poniendo de este modo en evidencia quiénes hablan y la posición desde la que actúan: los hombres sexistas, independientemente de su posición social, política, étnica o religiosa (Boscán, 2011, p. 175).

A través de las epistemologías críticas, como lo menciona Boscán, las mujeres han podido identificar que las categorías utilizadas por las ciencias son un velo para blindarse del carácter social y de las críticas que las feministas han venido realizando en el curso de las investigaciones. Todo el trabajo que ha hecho la filosofía de la ciencia para delimitar el acceso de las mujeres y para sacralizar a las ciencias, ha motivado reacciones significativas de parte de las ECF y de algunos epistemólogos críticos que han identificado que las ciencias requieren asistencia, para continuar con procesos investigativos que atiendan de cerca las necesidades que la humanidad va identificando, de esta forma, se va a aproximar el saber científico a lo que se defiende como verdades científicas. 


\section{Epistemologías Críticas Feministas}

Con la incursión de las mujeres en la filosofía de la ciencia se ha podido denunciar, como afirma Colás (2004), la doble incidencia que posee el sesgo androcéntrico de las ciencias. Por un lado que «provoca discriminación en la mujer para el acceso a la ciencia, y por otro, es la causa de la 'mala ciencia' y resultados 'sesgados' precisamente por la posición subjetiva e interesada del investigador, condicionada por una posición y rol determinado» (p. 3). En ese caso, el autor propone que esta perspectiva epistemológica:

Denuncia las concepciones y prácticas de investigación que excluyen las experiencias de las mujeres, niegan su condición de sujeto protagonista de la vida social, cultural, jurídica; niegan su autoridad epistémica denigrando sus estilos cognitivos y modos de conocimiento 'femeninos'; producen teorías sobre las mujeres que las representan como inferiores, desviadas o significativas solo en la medida en las que sirven a los intereses de los hombres; teorías sobre los fenómenos sociales que invisibilizan las desigualdades y que producen conocimiento que no es útil para las personas y que refuerza las distintas jerarquías sociales (Andersen, 2010, como se citó en Del Moral, 2012, p. 60-61).

Es decir, para las ECF, una forma de contrarrestar las limitaciones de la ciencia y de la filosofía de la ciencia, es aumentar el número de mujeres que reflexionan y participan en estos campos, pero sobre todo incorporar en este quehacer las teorías feministas y la categoría de género como concepto analítico. Según Andersen, después de que las mujeres tuvieron acceso a la educación superior y de poder revisar de cerca los textos científicos, encontraron la falta de fidelidad frente a la verdad que la ciencia pregonaba, pues, las inconsistencias que presentaban algunos postulados, conceptos y marcos teóricos en torno a la naturaleza de las mujeres, la neutralidad de las ciencias, entre otras categorías, carecían de veracidad científica. Los textos y la historia manifestaban de alguna forma, que habían sido acuñados para impedir el acceso de las mujeres al ejercicio científico.

Para algunos, la visión de las mujeres no solo es doble y amplia, sino también más proyectiva, pues resulta más previsora y esperanzadora que la de los hombres, ya que suponen que tienen una visión familiar y ecológica, una visión completa casi cosmológica (Boscán, 2011). En esta 
investigación sostenemos que el acceso de las mujeres como sujetos de conocimiento, ha generado una perspectiva más amplia del saber científico, de la filosofía y de la historia. La ciencia tienen como objeto de investigación un mundo más amplio y diverso que le permitirá descubrir no quizá verdades universales y objetivas como se ha venido pregonando, pero si más útiles, eficaces y equitativas para la humanidad.

El acceso a la educación que las mujeres lograron y el hecho de ser reconocidas como sujetos de conocimiento ha sido fundamental para empezar a fracturar los estereotipos de género que existían en contra de la escolarización y la profesionalización de las mujeres, se abre un espacio nuevo en la sociedad y en la estructura social de la ciencia.

Las mujeres han ganado terreno en el campo de lo científico, ya no son el objeto o el cuerpo extraño que hay que investigar, son el sujeto que investiga y que gestiona en el campo laboral. Las ECF hacen parte de este proceso de incorporación y han puesto en tela de juicio los mitos sobre la ciencia tradicional, han identificado las debilidades del ejercicio científico, postulando alternativas para hacer de las ciencias una práctica más transparente y humana de la que se venía realizando. En conclusión el acceso a la educación y la participación en el mundo laboral científico de las mujeres es una forma de contrarrestar la estructura desigual de la ciencia y de la sociedad.

\section{Experiencias de las mujeres y de «otros»}

El estereotipo social que se ha construido sobre las mujeres - como se mencionó en el apartado titulado objetos de estudio de este capítulo-, radica en mostrar la naturaleza femenina en un lugar diferenciado e inferior en relación con la posición jerárquica que tienen en la sociedad los hombres, un otro subvalorado y extraño que debe ser objeto de investigación para poder humanizarlo y que por ende, no tiene las cualidades para ser sujeto de conocimiento.

Una de las posturas de las ECF es justamente esta posición marginal la que otorga a los feminismos un puesto privilegiado frente al alcance del conocimiento, que permite a las mujeres una perspectiva más completa y desprovista de prejuicios, una perspectiva que algunos hombres 
no alcanzan por la posición privilegiada en la que se encuentran. De esta forma, el objeto extraño (las mujeres o la clase menos favorecida), logra percibir el mundo con mayor claridad, convirtiéndose a sí misma en el nuevo sujeto de investigación que cuestiona y critica la realidad que las ciencias han retratado de manera parcial.

Reflexionar sobre las experiencias de las mujeres, según las ECF, es contundente para evitar que las ciencias refuercen ese sistema cerrado de verdades definitivas e inmutables con el que se han venido identificando. La cientificidad de un discurso no estriba en la afirmación dogmática ni de sus procesos ni de sus contenidos. «Las ciencias se caracterizan por ser sistemas históricos y culturales y, por lo tanto abiertos» (Salazar, 1993, p. 93), que han surgido como producto de las necesidades humanas y no a través de la reflexión y experimentación arbitraria u inoficiosa de un investigador. Como dice E. Nicol: «cuyas conclusiones tienen siempre el carácter de hipótesis. En vano puede el hombre aspirar a que nazca un absoluto de su propio ser contingente, a que surja de la actividad temporal de su pensamiento un sistema intemporal de verdades» (E. Nicol como se citó en Salazar, 1993, p. 96).

Otra de las posturas de las ECF consiste en revisar las dicotomías que dividen el mundo y ubican a hombres y mujeres de forma separada en cada una de ellos. Al mirar los textos de historia universal y de las ciencias con los que nos han formado, nos damos cuenta que las experiencias femeninas y los ámbitos relacionados con ellas (mundo privado, la naturaleza y el saber tradicional) han sido subvalorados. La constitución de la ciencia androcéntrica ha supuesto la conceptualización y configuración de una perspectiva que marca el punto de vista de los varones y que se plasma en la estructuración del pensamiento en categorías dicotómicas como son: Público y privado; objetividad y subjetividad; razón y sentimiento. La parcelación de la realidad así establecida conlleva juicios de valor sobre los aspectos señalados al realizar una jerarquía sobre lo socialmente valorado. La preponderancia los adquieren los problemas, teorías y acontecimientos masculinos, en cambio, los problemas, teorías y acontecimientos femeninos son en muchas ocasiones dados por obvios e irrelevantes.

Las filósofas de la ciencia han generado diversas teorías y críticas que cuestionan esta división del mundo y el supuesto de que las mujeres y los hombres ocupan una parte específica de esa 
dicotomización. Por ejemplo, juzgar lo privado como una realidad ajena a lo público o desconocer que el mundo de la vida íntima (privada) no hace parte de la vida de los hombres. También señalan que para contrarrestar algunas limitaciones de la ciencia (como aquella que ubica a las mujeres como un objeto de estudio), es necesario desmitificar las concepciones adscritas al género masculino (lo público, el poder, la conquista, la competitividad) el cual ha estado históricamente diseñado y proyectado a futuro para beneficio y reconocimientos de los hombres (Harding, 1996 y David, 1994).

Los debates mencionados en el transcurso del texto hacen parte de las evidencias que ponen a las mujeres al otro lado del proceso investigativo, ellas ya no son objetos de estudio sino sujetos de investigación. Cada una de las denuncias aquí expuestas, demuestran que se ha realizado un trabajo riguroso y serio en favor de mejorar las condiciones del saber científico. No hay que desconocer - dice Harding-, que hacemos parte de una cultura científica y que la racionalidad científica no solo está presente en todas las formas de pensamiento y de acción de nuestras instituciones públicas, sino, incluso en nuestras formas de pensar sobre los detalles más íntimos de nuestra vida privada.

\section{Universalismo y conocimiento situado}

Para contrarrestar los sesgos en los conceptos, los marcos teóricos y la definición de los problemas de investigación, las ECF proponen descentralizar el saber e incorporar la noción de conocimiento situado. Esta perspectiva busca que al posibilitar a todos los investigadores independientemente de la clase social, el género, o cualquier tipo de condicionamiento impuesto hasta el momento, puedan ampliar y ver las deficiencias en el tipo de conceptos, teorías y problemas que se utilizan en las ciencias.

A través de la noción del conocimiento situado, las ECF cuestionan que el saber científico se produzca en un laboratorio descontextualizado de la realidad, y afirman que el conocimiento científico no está desligado de la realidad social y humana del investigador. Fundamentalmente, los postulados del conocimiento situado surgen como reacción a la categoría de universalidad que la filosofía de la ciencia ha planteado como parte de los criterios de verdad y validez. Esta 


\section{Epistemologías Críticas Feministas}

categoría que utilizan las filosofías de la ciencia, normaliza el saber e impide que existan sujetos y contextos en plural que produzcan ciencia, favorezcan espacios concretos y diferentes en donde se pueda hacer ciencia. Sin negar que todo conocimiento científico es cultural y está condicionado por el contexto, la universalidad en las ciencias no es un asunto menor. Hay leyes universales en la naturaleza.

Cruz, Reyes y Cornejo (2012), en el artículo Conocimientos situados y el problema de la subjetividad del investigador, van a elaborar una crítica en torno al debate que ha surgido ante la posibilidad de seguir operando con un concepto de ciencia y de conocimiento científico que funda gran parte de su rigurosidad en la exigencia de objetividad entendida como sinónimo de neutralidad. Para tal efecto, van a abordar la perspectiva del conocimiento situado

Que, por una parte, sostiene que las versiones del mundo que co-construimos en la investigación no son meros relatos fantásticos o un discurso como cualquier otro, mientras que por otra, reconocen la imposibilidad de plantear que el conocimiento refleja una realidad de manera neutra, más aún si asumimos que éste se nutre de inquietudes ciudadanas, políticas e ideológicas de los investigadores (p. 253-254).

También se debe reconocer como supuesto de la epistemología de los conocimientos situados «que el investigador es parte constitutiva del mundo que se despliega desde la investigación [...] pero también que los investigadores somos parte de lo investigado, que afectamos y somos parte de nuestros objetos de estudio» (p. 253-254).

Donna Haraway (1995), realiza un análisis de la ciencia y la tecnología, a partir de su postura epistemológica, para rechazar la existencia de conocimientos objetivos. Todo saber, según la autora, es siempre una construcción hecha desde una perspectiva determinada, que es influenciada por esta. Por ende, se debe reconocer el arduo trabajo que se ha realizado desde el conocimiento situado frente al «poderosísimo argumento construccionista, que no dejaba resquicios para reducir los temas a parcialidad contra objetividad, a buen uso contra mal uso o a ciencia contra pseudociencia (Haraway, 1995, p. 319), y afirma: «Desenmascaramos las doctrinas de la objetividad porque amenazaban nuestro embrionario sentido de la subjetividad y 


\section{Epistemologías Críticas Feministas}

de la función colectiva histórica y nuestras definiciones de verdad» (p. 319). Para la filósofa es indispensable que el investigador concentre su atención en lo particular, el contexto del sujeto cognoscentes es el objeto de estudio, porque es concreto, vivencial y porque de él surgen los problemas y las posibles soluciones que necesita comprender. El concepto de objetividad tiene en esta perspectiva características diferentes a la tradicional

Así de manera no tan perversa, la objetividad dejará de referirse a la falsa visión que promete trascendencia de todos los límites y responsabilidades, para dedicarse a una encarnación particular y específica. La moraleja es sencilla: solamente la perspectiva parcial promete una visión objetiva [...] La objetividad feminista trata de la localización limitada y del conocimiento situado, no de la trascendencia y el desdoblamiento del sujeto y el objeto. Caso de lograrlo, podremos responder de lo que aprendemos y de cómo miramos (Haraway, 1995, p. 326-327).

Esa perspectiva parcial está constituida por nuevos conceptos, nuevos problemas y nuevas teorías que defienden como otra de sus tesis fundamentales, el surgimiento de la ciencia como resultado del análisis de experiencias diversas, donde se incluye el sujeto investigador y su entorno. Según Del Moral (2012) es una diversidad de conocimientos que incorpora

Lo que se conoce y el modo en que se conoce, refleja las experiencias, circunstancias y perspectivas físicas, psíquicas y sociales particulares de los sujetos; es decir no solo su corporalidad, sus valores, sus habilidades, sus estilos cognitivos, sus relaciones epistémicas con otros sujetos cognoscentes, sino también su localización social: género, orientación sexual, raza, etnicidad, edad, estatus familiar, roles y relaciones sociales - ocupación, pertenencia a un partido político-, su identidad social atribuida y su identidad subjetiva ( $\mathrm{p}$. 62).

En la ciencia, en sus conceptos, teorías y problemas, está inmersa toda la realidad social que comprende al sujeto investigador y al objeto investigado. El resultado de la investigación no es otra cosa que la mediación entre uno y otro. Hay que tener en cuenta que los dos (sujeto y objeto, cada uno desde la subjetividad que los conforma), son realidades mudables y predeterminadas 
por circunstancias específicas, el clima, la temperatura, la cultura. y que los dos estarán indiscutiblemente involucrados en los resultados finales que surjan.

Aunque los críticos -dice Harding (2003), aseguren que la teoría del punto de vista ha abandonado los conceptos epistemológicos de verdad, objetividad y buen método (p. 7), no es así; se han transformado y se han hecho más asequibles a la realidad científica que presenciamos constantemente. Por ello, las diversas aportaciones y experiencias en contextos situados, la elaboración de métodos y teorías que fundamenten una posible objetividad desde la multidimensionalidad del pensamiento, son una necesidad si se quiere fundamentar la ciencia desde perspectivas diversas y basadas en la realidad cambiante que nos circunda.

Villarmea (1999), desde la teoría del punto de vista compila la finalidad de las críticas epistemológicas feministas en cuatro características fundamentales: 1) resaltan la constante transformación que experimentan las circunstancias, los agentes de conocimiento y las tesis cognoscitivas; 2) defienden que los conocimientos están situados, es decir, que están marcados por las orientaciones de partida; 3) señalan que la importancia de aclarar la posición desde la que se elabora el conocimiento es proporcional a la responsabilidad que asuma el agente de conocimiento; 4) luchan porque el discurso cognoscitivo se construya desde aquellas perspectivas que lleven a resultados más liberadores (p. 225).

En el cuarto punto de Villarmea, otro desafío que formulan las ECF resulta ser la pericia heroica al conocimiento edificante. El texto hace referencia a las consecuencias y responsabilidad social del quehacer científico. La ciencia moderna, y por consiguiente, la teoría crítica moderna, se basaron en el presupuesto de que el conocimiento es válido independientemente de las condiciones que lo hacen posible y de las consecuencias que pueda acarrear, por eso, su aplicación se independizaba igualmente de todas las condiciones que no fuesen necesarias para garantizar la operatividad técnica de la aplicación. La construcción de esta operatividad se daba a partir de la falsa equivalencia de escalas, en las cuales se producía y ocultaba el desequilibrio existente entre la acción técnica y las consecuencias de la misma. Santos Boaventura de Sousa (2000) afirma: 


\section{Epistemologías Críticas Feministas}

A causa de este desequilibrio, la gran escala de la acción se coloca al mismo nivel que la pequeña escala de las consecuencias. Esta falsa equivalencia de escalas es fundamental en este paradigma de conocimiento. Dado que la ciencia moderna desarrolló una capacidad enorme de actuación, pero no desarrolló una correspondiente capacidad de prever, las consecuencias de una acción científica tienden a ser menos científicas que la acción científica en sí misma. Este desequilibrio, y la falsa equivalencia de escalas que lo oculta, posibilitan el heroísmo técnico del científico. Una vez descontextualizado, todo el conocimiento es potencialmente absoluto. Esta descontextualización hizo posible el tipo de profesionalización que hoy domina. A pesar de que la situación parece estar cambiando, todavía es muy fácil producir o aplicar conocimiento escapando a las consecuencias. La tragedia personal del conocimiento solo puede ser detectada en las biografías de los grandes creadores de la ciencia moderna de finales del siglo XIX y principios del XX (p. 32-33).

La ciencia debe prever además del funcionamiento técnico de las investigaciones y experimentos, la utilidad y el impacto social que pueda generar en la sociedad. La finalidad de la ciencia no se debe apartar del objetivo primordial de todo saber humano: la preservación de la integridad de la humanidad, del medio ambiente y el mejoramiento de la calidad de vida.

Diana Maffia, insiste en demostrar que el referente de verdad debe considerarse a partir de la relación intrínseca y extrínseca del investigador con el objeto y de estos dos con el contexto. Según Maffia (2007):

Hablar de una reconstrucción feminista de los saberes científicos es hablar de una reinterpretación desde la perspectiva de género, y del aporte que desde ella pueda hacerse para la emancipación de las mujeres. Para ello se concebirá a la ciencia como una construcción por parte de una comunidad en la que influyen otras variables sociales además de los parámetros disciplinarios, y cuyo producto no debe ser confinado para su estudio al desarrollo dentro de la comunidad científica. Deben analizarse motivaciones y consecuencias del ejercicio de la ciencia, la intervención de intereses no reducidos al 


\section{Epistemologías Críticas Feministas}

impulso epistémico los sesgos no visibles por formar parte de valores compartidos por la comunidad científica (p. 83-84).

No se trata de sustituir una estrechez mental por otra, ni de complementar perspectivas masculinas y femeninas, «sino más bien de una transformación de las categorías mismas de masculino y femenino, de mente y naturaleza. Buscando así unas ciencias que permitan la multiplicidad, la supervivencia productiva de diversas concepciones del mundo y sus correspondientes estrategias» (Maffia, 2007, p. 69). Las investigaciones científicas se deben realizar para mejorar las condiciones humanas; esa debe ser la finalidad, más que la pretensión de universalidad e inmutabilidad de las ciencias.

En el primer capítulo hicimos referencia a los cambios presentes en el conocimiento científico a lo largo de la historia y la importancia, en su momento, de la ruptura de los paradigmas imperantes. En este capítulo se han mostrado las posibilidades que tiene el saber científico si logra reconocer lo fundamental de exponerse al examen constante para identificar las debilidades y errores que han viciado el ejercicio teórico y práctico de las ciencias.

El saber científico no se debilita al encontrar debilidades en los planteamientos y descubrimientos que realiza, sino por el contrario, se aproxima con mayor posibilidad al esclarecimiento de los objetivos que se ha trazado. El impacto que han generado las epistemologías críticas y las ECF hasta el momento ha sido positivo, pero es indispensable mostrar en todas las instituciones que se encargan de reproducir el saber científico que el conocimiento no adquiere valor por el carácter universal, ahistórico, neutral y objetivo, sino por la posibilidad de cometer errores, de corregirlos en el seno de la sociedad desde donde se crea y para la cual se destina. 


\section{Epistemologías Críticas Feministas}

\section{CAPITULO III. EDUCACION PARA LA EQUIDAD DE GÉNERO DESDE LAS PERSPECTIVAS EPISTEMOLÓGICAS CRÍTICAS FEMINISTAS}

El propósito de esta investigación es identificar las oportunidades ${ }^{9}$ que las epistemologías críticas y las epistemologías críticas feministas nos pueden brindar en los procesos de enseñanzaaprendizaje de la Educación Primaria y Secundaria. Después de haber conocido las fortalezas, las debilidades de la creación, ejecución y distribución del conocimiento científico, así, como del papel de las mujeres y hombres que no figuran en esta importante labor, el interés de este capítulo consiste en generar una reflexión crítica para determinar cuáles serían las posibles alternativas que tienen los procesos de enseñanza-aprendizaje formulados de manera equitativa, libres del sesgo androcéntrico implícito del saber científico.

En el capítulo I se realizó un recorrido por los planteamientos epistemológicos del siglo XX, enfocándonos principalmente en Thuillier y Harding, quienes nos proporcionaron la postura epistémica que queríamos vislumbrar y aplicar en el desarrollo del trabajo, por supuesto de la mano de otros pensadores y pensadoras, teniendo como referente, la relación ciencia y sociedad.

En el Capítulo II se mostró cómo la ciencia ha extrapolado el velo del sesgo androcéntrico y cómo se hizo imperativo e implícito en las ciencias en casi todas las instituciones sociales, dejando a las mujeres en el rincón de cualquier posible representación social, cultural, política y religiosa; pero también, cómo ese tipo de marginación dio pie a un grupo de mujeres y hombres preparados que se han dedicado a revertir los efectos de lo que en palabras de Harding se denomina simbolismo de género ${ }^{10}$, estructura de género ${ }^{11}$ y género individual. Estos estereotipos han inutilizado la participación de las mujeres, al mismo tiempo que abrieron la discusión en los feminismos para reestructurar las instituciones sociales y la ciencia misma.

Este significativo, pero al mismo tiempo limitado, panorama epistémico nos va a brindar las herramientas para realizar una reflexión en torno a las prácticas pedagógicas que nuestras instituciones educativas distritales están llevando a cabo. Instituciones que por su carácter tienen

\footnotetext{
${ }^{9}$ Pedagógicas, curriculares, convivenciales y humanísticas para los procesos de enseñanza y aprendizaje.

10 «O, tomando una expresión de la antropología 'totetismo de género'» (Harding, 2006, p. 17).

11 «O división del trabajo según el género» (Harding, 2006, p. 17).
} 
como compromiso reproducir la cultura y la ciencia, pero con la responsabilidad de hacer de ese aprendizaje, un ejercicio dinámico y crítico; ingredientes que quizá por la rutina del ejercicio, por la misma estructuración curricular o por la falta de actualización docente, aún es estrecha, en relación con algunas cuestiones que son de suma importancia para la consolidación de una sociedad más integra y responsable en relación con los efectos que el género produce en todas las instituciones de la sociedad.

La pregunta de investigación se dirigió inicialmente a describir cómo a partir de la identificación de algunas teorías epistémicas tales como: Las epistemologías críticas, las epistemologías críticas feministas, y la epistemología "especial”, es posible reflexionar sobre procesos educativos más equitativos en la formación de hombres y mujeres, con procesos académicos que no reproduzcan el sesgo androcéntrico implícito de las ciencias. Es decir, procesos de enseñanza-aprendizaje que ejerciten la perspectiva de las ECF, que se encuentren al margen de los dogmatismos universalistas, que no estén blindados ante la posibilidad de reinterpretarse en la historia, de adaptarse en los contextos y de reevaluarse constantemente.

La Epistemología Crítica Feminista debe convertirse en una herramienta asequible, abierta y equitativa para examinar e implementar los procesos de enseñanza-aprendizaje de la educación Básica y Medía, que le permita al sujeto deconstruir el saber a partir de sus necesidades y reconstruirlo de acuerdo con el tipo de realidad que esté reconociendo. En donde la descentralización de las perspectivas epistémicas sesgadas y androcéntricas sea una posibilidad frente a las epistemologías emergentes.

Se ha podido evidenciar en este ejercicio que existe una ruptura significativa entre la ciencia, la historia y la sociedad, coincidimos con Thuillier, Harding, Morin, entre otros, que en esta fractura epistémica ha atravesado de manera horizontal y vertical por todas las instituciones sociales sin excepción, esa desviación o debilidad de la ciencia se ha denominado el sesgo androcéntrico, que, aunque es imperceptible por su naturalización, polariza la perspectiva de los hombres y de las mujeres, éstas últimas, condicionadas además por el rol sociocultural que se le ha atribuido, siendo usado como mecanismo de invisibilización en la historia, en la que el hombre ha asumido la representación absoluta en todas las dimensiones de la sociedad. 
Ya dijimos anteriormente que ha existido un impacto positivo en la epistemología y en las ciencias a raíz de las críticas que se han realizado en círculos de intelectuales emergentes, como en los feminismos y otros grupos de epistemólogos de las ciencias; los logros alcanzados por algunas mujeres, en algunos campos de la ciencias, constituyen evidencia sobre el impacto que ha tenido las ECF. Entre ellas Sandra Harding, los premios Nobel en ciencias que han alcanzado mujeres que anteriormente se mencionaron y la implementación de convocatorias de entidades, instituciones, corporaciones entre otras para que las mujeres continúen involucrándose de formas diferentes, en el quehacer científico y en la transformación que este quehacer ha tenido.

Lo anterior nos permite revisar el siguiente cuestionamiento: si la educación ha normalizado un discurso en favor de lo masculino ¿cómo subvertir a través de la educación el carácter androcéntrico de los procesos de enseñanza aprendizaje? Son evidentes las falencias que ha tenido la educación como mecanismo de transmisión de la ciencia, gracias a conceptos como neutralidad, objetividad, universalidad, ahistoricidad e imparcialidad.

¿Hasta qué punto, una perspectiva con algunos grados de relatividad puede considerarse como la opción más cercana para alcanzar un saber verdadero? ¿Qué papel juega el género en el ejercicio científico? ¿Qué transformaciones presentarían las ciencias y la sociedad si se empieza desde la Educación Básica y la media, a mostrar el mundo desde una perspectiva epistemológica crítica feminista a los hombres y mujeres que se están formando?

En este capítulo se sugieren tres ideas que a partir de las ECF se pueden incorporar en el quehacer pedagógico: El docente y los estereotipos de género, los currículos y la perspectiva de género; $y$, el estudiante y la perspectiva de género.

\section{El docente y «los estereotipos de género»}

En el capítulo uno de esta investigación decíamos que la filósofa norteamericana Sandra Harding, haciendo alusión a Rossiter, mostraba cómo los estereotipos o el simbolismo de género han creado en hombres y mujeres modelos de géneros desiguales e inequitativos. En muchos 
casos son las mujeres las principales reproductoras del modelo androcéntrico de las ciencias y por falta de conocimientos, e incluso por temor a ser tildadas de reaccionarias o feministas omiten la necesidad e importancia de dar a conocer las debilidades que presenta la ciencia frente al género, la historia y la sociedad.

Estas son algunas de las razones por las que no todas las mujeres se arriesgan a ser críticas con los modelos de las ciencias tradicionales, de cómo estas explican también de manera sesgada las vidas de las mujeres y en consecuencia el rol de estas en la sociedad. A partir de las ideas de ciencia que se suelen reproducir, como ya se mencionó, la ciencia es racional, porque es rigurosa, porque posee un método, porque es neutral y objetiva, todo lo contrario a lo que se cree de las mujeres, quienes tienen una naturaleza opuesta a estos rasgos (suaves, delicadas, emocionales, no competitivas y asistenciales), es decir, no encajan con los estereotipos sociales de la ciencia, como lo enuncia Harding.

Estos estereotipos de género y de la ciencia se reproducen en la escuela, donde se dice que las mujeres no son aptas para la ciencia, en especial para las "ciencias duras". Así, han naturalizado la idea de estar destinadas al servicio de los quehaceres domésticos, o en roles de apoyo a las labores de los hombres y que los trabajos o tareas a desempeñar es el de auxiliares según como se ha enmarcado en la «estructura de género» imperante. Esto, como ya hemos dicho se reproduce en la estructura social de las ciencias.

Aunque actualmente algunas mujeres ingresan a las facultades de ciencias, ingenierías, tecnología, el número de ellas es menor en estas disciplinas en comparación con la demanda de los hombres en las mismas facultades. Además, académicas como Fox Keller, Bárbara MClintock o Donna Haraway afirman que son lugares agresivos en los que les recuerdan que son espacios masculinos y que por eso tendrán que esforzarse mucho más para demostrar que pueden pertenecer a estos lugares. Son carreras que se caracterizaran por hacer parte de las ciencias duras, rigurosas, impersonales, masculinas, competitivas y no emocionales y por eso se limita la participación y el tipo de proyectos que una mujer podría desarrollar. Se ve y se motiva a que las mujeres se desempeñen en labores menores o complementarias tales como secretarias, auxiliares, entre otras. 
Las instituciones educativas pueden incentivar a las mujeres y a los sectores menos favorecidos para que se incorporen a estudiar las mal llamadas «ciencias duras», promoviendo actividades que motiven a los estudiantes y las estudiantes a superar los estereotipos que se han implementado tras los modelos educativos vigentes. Para lograr esto es muy importante primero formar a los maestros y maestras, pues no han sido la excepción frente a esta especie de injusticia y encubrimiento teórico: el androcentrismo en las ciencias.

El maestro (a) ha sido educado en un modelo basado en estereotipos de género, es decir, su enseñanza se fundó en referentes bibliográficos masculinos, la historia que conocieron fue forjada por hombres ilustres, así como los descubrimientos, las revoluciones, los avances científicos, todo acondicionado para que el mundo tuviese como protagonista la figura del hombre y de esta forma se continuara reproduciendo una mirada masculina.

En el capítulo dos retomamos a Pilar Foz y Foz para mostrar cómo se impartía la educación en Colombia en el siglo XIX y el siglo XX; vemos con asombro, que ese mismo modelo educativo se ha extrapolado con algunas modificaciones mínimas y se ha seguido implementando en las últimas décadas. Esto para decir que el docente y la docente son herederos en su mayoría de un tipo de educación netamente androcéntrica, cargada de los estereotipos de género. Se puede evidenciar lo anterior en los currículos, en los planes de estudio, en los manuales de convivencia, en la distribución de los espacios físicos del plantel educativo, e incluso, en el uso del lenguaje en frases como: así no se sienta una señorita, ese no es el lenguaje de una dama, no actué como un hombre, no sea nena que usted es un varón, no actúen como niñitas, las mujeres son buenas secretarias y los hombres buenos ingenieros, las cuales continúan motivando los tres aspectos del género que enuncia Harding: El simbolismo de género, la estructura de género y el género individual.

La formación de los docentes en la equidad de género, debe incluir una historia crítica de las ciencias que incorpore el proceso de construcción social, las fases de profesionalización y las luchas que han realizado las mujeres para tener acceso a la educación y al mundo laboral. Adicionalmente, los docentes deben conocer los nombres y los logros de las mujeres que han 
sobresalido en las ciencias, en las artes, en la literatura, para que se den cuenta de la importancia que tienen ellas en el desarrollo del pensamiento, y por ende, la necesidad de alimentar constantemente la crítica sobre el conocimiento científico y sobre la realidad social.

Los estereotipos sobre cómo son los científicos deben ser analizados, en especial las aseveraciones sobre el carácter rígido o sensible que se le ha asignado a uno y otro sexo, el carácter despectivo que se le atribuye a la delicadeza y al sentimentalismo no pueden continuar figurando como el estereotipo de la debilidad y como opuesto a la ciencia. Harding resaltaba que los sentimientos y las conductas delicadas no son propios de las mujeres, son propios de los seres humanos y del conocimiento científico. Millman y Kanter, citadas por Harding, también encuentran relevante el significado de los sentimientos como conductas propias de los investigadores e investigadoras de las ciencias, que no por ello dejan de ser humanos.

La dificultad de la mayoría de maestros es el desconocimiento que tienen sobre los estereotipos de género, porque no identifican la existencia de estos en el quehacer educativo. Una de las razones es que estos docentes fueron educados con parámetros androcéntricos, en donde la historia social y la historia de la ciencia eran encasilladas como netamente masculinas, ocultas bajo la idea mitológica de que la ciencia es neutral, infalible y que se debe enseñar como verdades inamovibles. No han aprendido a problematizar el saber científico y transmiten ciertas verdades de la ciencia como contenidos sagrados. En este proceso han naturalizado la historia, la estructura social y el contenido de la ciencia y no se preguntan por qué ese lugar subalterno de las mujeres en esa historia y en esa estructura.

Es imperativo para propiciar una educación desde la equidad de género que los docentes cambien la perspectiva que manejan sobre el género, la ciencia y sobre la relación que existe entre esos dos ámbitos. Identificar que el género y la ciencia hacen parte de una construcción cultural y ver la forma como ambos escenarios se enriquecen si se cuestionan y problematizan.

La desinformación es fundamental cuando se quiere seguir manteniendo paradigmas que no conviene que sean reestructurados y más si las relaciones de poder que se han establecido giran en torno a ellos. El docente es un medio de información y está incrustado en ese engranaje del 
sistema social, que ha llevado a algunos maestros a conformarse con los conocimientos básicos que fueron adquiridos en los estudios de pregrado, y que han limitado desde diversas circunstancias la iniciativa del docente de optar por prácticas investigativas autónomas y colectivas. El sistema, la cultura y las políticas estatales condicionan al docente (a falta de tiempo, de recursos para actualizarse, de espacios para la investigación) a poner en práctica teorías e hipótesis pedagógicas y científicas sin el examen y estudio respectivo para corroborar su veracidad, exponiendo la credibilidad de su discurso al simple hecho de venir de una autoridad académica, convirtiéndose desinteresadamente en contribuyente de la desinformación y tergiversación de la realidad.

El desconocimiento y los prejuicios que manifestaron los profesores que integraron el seminario $^{12}$ (masculinidades y feminismos) sobre el género, confirman que los docentes no tienen la formación o los conocimientos adecuados y necesarios para plantear un modelo de educación equitativa para los y las estudiantes. A pesar de las conferencias y las publicaciones que se han realizado alrededor de los diversos feminismos, se requiere compromiso y rigurosidad académica si se pretenden modificar los modelos pedagógicos, curriculares y epistemológicos que por siglos se han venido reproduciendo con apariencias siempre diferentes, que mantienen la normalización androcéntrica, y solapada en los diferentes discursos de la academia.

Las instituciones educativas deben motivar a las mujeres para que se incorporen a estudiar las ciencias, pero para ello, es necesario: primero, convencer a los maestros de la importancia de incluir los estudios de género en la educación; y segundo, identificar que la neutralidad en el conocimiento y en la educación no existe y que esta es razón suficiente para articular el saber científico, la historia y el género. Hay que mostrar a los estudiantes desde la educación Primaria y la Secundaria las críticas que desde las epistemologías críticas y las ECF han surgido en torno al proceder de las ciencias. También es necesario remover los estereotipos sobre el género individual, el simbolismo de género y la estructura de género, para reconocer: 1) que las mujeres sí han tenido representación histórica, aunque sea mínima; 2) que las capacidades cognitivas y actitudinales de las mujeres son óptimas para el ejercicio de cualquier disciplina; y 3) que la

\footnotetext{
${ }^{12}$ Seminario "Masculinidades y Feminismos" orientado por la Maestra Claudia Giraldo en el primer semestre del año 2016, como parte de las materias electivas de la Maestría en Filosofía de la Universidad Santo Tomás.
} 
estructura social de género ha vulnerado el derecho a la igualdad y la equidad de la que puede disponer todo ser humano.

De la mano del cambio de perspectiva sobre el género, transformar los modelos pedagógicos y didácticos es crucial para implementar la equidad de género en la educación Primaria y Secundaria. Los procesos de enseñanza-aprendizaje bajo la autoridad de los maestros, por omisión o ignorancia han continuado naturalizando la idea de que las mujeres son débiles y que los hombres son fuertes; que las mujeres son sensibles y que los hombres son racionales. Estas dicotomías han llevado a que algunas personas consideren, que las ciencias son un campo exclusivo para los hombres.

Se trata de problematizar la supuesta relación entre profesión, roles de género y sexo biológico para ampliar las posibilidades de elección de la profesión de los hombres y las mujeres, para que puedan asumir tareas diferentes a las enmarcadas para «cada género». Esto podría a largo plazo cambiar el simbolismo de género que se ha impuesto desde la familia, la escuela y el campo laboral. Los hombres y las mujeres tendrían menos prejuicios o miedos para desenvolverse en cualquier campo disciplinario o laboral, y así combatir la construcción de la identidad masculina basada en la subalternidad femenina.

\section{Los currículos y la perspectiva de género}

En este apartado proponemos la forma como pueden incorporarse a la educación las experiencias de las mujeres, para problematizar las dicotomías en las que se ha dividido el mundo. Hemos titulado este apartado Los currículos ${ }^{13}$ y la perspectiva de género, porque sostenemos que deben ser equitativos, para que puedan mostrar indistintamente las propuestas de la epistemología tradicional, de la epistemología crítica y de las ECF. Desde esta perspectiva, los educandos van a

\footnotetext{
13 Entendemos por currículo el campo de estudio. Comienza con Franklin Bobbit en 1918, con el texto The Curriculum y en 1924, How to make a curriculum $^{13}$; con Clarence Kingsley y el texto Los Principios Cardinales de la Escuela Secundaria. Después de la II Guerra Mundial, ocurre en Estados Unidos un marcado crecimiento industrial, urbanizaciones, desarrollo tecnológico. Esto tiene efecto en lo económico y en lo político y como resultado, los programas sufren cambios. Las fuerzas de poder empiezan a influenciar para que los programas sean más prácticos (utilitarios) y eficientes.
} 


\section{Epistemologías Críticas Feministas}

reflexionar de manera crítica la forma de articular el conocimiento con la realidad en la que habitan, antes de generar frente a una u otra propuesta epistemológica algún prejuicio que reste imparcialidad a sus conclusiones.

Los discursos científicos, según afirma Salazar (1993), nunca logran en sí mismos, establecer unas condiciones absolutamente 'asépticas' de su constitución y de sus contenidos. (p. 55) y por ende, se debe superar esta tendencia. Una de las formas de hacer posible esta perspectiva, es generando reflexiones críticas en los educandos frente a los modelos de enseñanza-aprendizaje tradicionales. En ese proceso se pueden articular posturas, autores y contextos diversos frente a una misma hipótesis, que reflejen la dinamicidad del saber y el impacto relativo del sujeto pensante y del contexto.

En el capítulo dos, hablamos de la necesidad de humanizar la ciencia y para hacerlo, es necesario humanizar el currículo. Según Bobbit, se trata de minimizar las diferencias de clase, de género y devolverle la subjetividad al estudiante, es decir, dejando de identificarlo con un producto. Es indispensable la elaboración de un currículo flexible, que permita compilar las necesidades de los estudiantes y de la comunidad escolar en general, que cambie algunos artificios que la ciencia, la cultura han venido reproduciendo, tales como: el racismo, el clasismo, la misoginia, entre otros, que entorpecen las relaciones sociales, las reflexiones epistemológicas, la conformación de una ética basada en la equidad, el acceso equitativo a las actividades económicas, y que transversalmente, genere impacto en todos los procesos sociales sin excepción.

Es evidente la necesidad que existe en el campo educativo de una educación equitativa, que se encuentre al margen de lo que hemos identificado como el sesgo androcéntrico de las ciencias. Uno de los factores para impulsar esta perspectiva pedagógica es la capacitación docente. Seguidamente se debe revisar y adecuar cautelosamente el currículo como un texto de inclusión, en el que el género, la clase, el sexo, la etnia, se articulen de manera transversal con todos los procesos académicos y disciplinarios que se desarrollan al interior de la escuela. De esta forma, se promoverá la intención de disminuir la brecha existente entre las relaciones de «saber-poder» que la escuela por siglos ha venido reproduciendo. 
El análisis que se va a realizar en este apartado, se deriva de tres premisas que articulan la propuesta curricular de género: 1) el género es una construcción social que no reside en los individuos; 2) la escuela se ha encargado de introducir y reproducir los modelos androcéntricos implícitos en las ciencias, lo cual se evidencia en las elaboraciones teóricas del currículo, en el que se posponen las relaciones inequitativas en la relación saber-poder y 3) El currículo se debe referir a todo lo que sucede en el contexto escolar articulando el conjunto de prácticas institucionales que introducen las personas a una forma particular de vida, a una red de interacciones y relaciones.

Dado que el currículo no puede ser separado de los sujetos que lo median o de las situaciones sociales, culturales e históricas y los discursos que influencian a esas personas, se convierte en un medio eficaz para la transformación cultural que requiere cualquier proceso de equidad de género. El marco feminista crítico no solo es útil, sino necesario para leer el currículo en los procesos de escolarización, puesto que este ofrece formas inclusivas a partir del estudio de situaciones, contextos específicos no esencializantes, es decir, formas de incluir el mundo de las mujeres y de las minorías ${ }^{14}$. Esas otras partes de las dicotomías que no se abordan (el mundo privado, sensible, emocional), hay que verlas como focos epistémicos significativos para la interpretación y asimilación de las problemáticas y las posibles estrategias para su abordaje.

Carmen Rodríguez Martínez, confirma la importancia de incorporar las ECF a los procesos de enseñanza y aprendizaje, específicamente en la construcción del currículo. La autora afirma que en las sociedades en que la escolarización se ha convertido en un derecho y una obligación, hasta una edad determinada, el sistema escolar ejerce un papel decisivo, ya que establece los estándares para la elaboración del curriculum, como el recorrido que ha de seguir el conjunto de la población durante un periodo importante de su vida. Sin olvidar que este curriculum no es neutral.

El curriculum desde las epistemologías críticas feministas, según Harding, debe superar las falencias que presentan las teorías curriculares tradicionales. Debe empezar por minimizar la

\footnotetext{
${ }^{14}$ El termino se utiliza como categorización psicológica dentro de la demografía que se refiere a un grupo reducido de seres humanos que no son tenidas en cuenta por el Estado en lo político, público, social y económico.
} 


\section{Epistemologías Críticas Feministas}

brecha que la cultura ha generado en torno a las diferencias de género, lo que implica reconocer que el modelo de educación que se imparte en la actualidad es un modelo sesgado por el androcentrismo, ocasionando roles y actividades ficticias, las cuales, naturalizadas en la historia se han asumido como canon natural de las diversas culturas, en las que el hombre ejerce de manera autoritaria el rol de poderoso y las mujeres, minimizadas por la tradición, se muestra como el sexo frágil que debe ser protegido por el varón.

Como contribuciones para actualizar y mejorar el currículo se deben tener en cuenta algunos elementos que menciona Rodríguez en la segunda parte del texto. Según la autora, existen todavía algunos aspectos que siguen desequilibrando el curriculum escolar en contra de las niñas y mujeres: el androcentrismo de los textos como un referente de un humanismo que solo reconoce a los hombres (Amparo Moreno); los problemas que tienen las jóvenes en el acceso a las Tecnologías de la Información y la Comunicación (Carmen Rodríguez y Félix Angulo); el espinoso campo de la convivencia en las aulas y las desequilibradas relaciones que se producen entre chicos y chicas también en los centros educativos (Elena Simón) y una propuesta para introducir el tratamiento de las emociones, el cuerpo y la sexualidad en el aula (Charo Altable). Estas cuatro aportaciones nos proporcionan una imagen bastante limitada de cuáles son las problemáticas de las niñas y mujeres en los sistemas escolares actuales; problemas más ocultos y sutiles que en tiempos pasados, pero no por ello, con menores repercusiones en la formación de las niñas. Por ello -dice Rodríguez-:

El pensamiento humanista que asumimos en el Currículum escolar está viciado de raíz por prejuicios androcéntricos, que vician cualquier posición crítica que no afecte a esta raíz. Y que insista en la necesidad de definir el problema, no solo como un género, sino como androcentrismos término que condensa una problemática más compleja, de la que el sexo, o el género, es solo un aspecto que hay que considerar siempre articulado con otros, como la clase, la edad, el origen social (Rodríguez, 2004, p. 106).

Esa articulación de la que habla Rodríguez debe empezar en la escuela, a partir de la reestructuración teórica e ideológica del currículo, -como ya se ha mencionado- el currículum debe ser un constructo social, que minimice las fracturas de las relaciones interpersonales que las 


\section{Epistemologías Críticas Feministas}

tradiciones culturales y la ciencia han venido implementando. En tal sentido, el currículum debe ser emergente y plural, no puede pretenderse un modelo estándar, por el contrario, debe ser pluriforme y flexible. De esta forma, podrá recoger una perspectiva panorámica de las necesidades que el entorno le transmite, desde lo que normaliza y subsume la cotidianidad, hasta los contenidos, pedagogías y didácticas que se utilizan en el aula de clases.

Hombres y mujeres deben verse en esta perspectiva curricular no dentro de un paradigma cerrado de género, por el contrario, abiertos a la expectativa, en un constante proyectar, construyendo una sociedad y una cultura que no determine las potencialidades del individuo por su género, sexo, etnia, clase social o cultura y no se está hablando de una utopía donde todos sean felices a falta de la diferencia, todo lo contrario, se implementa la construcción de una sociedad en la que la diferencia no sea vista como una amenaza, sino como una oportunidad, en la que el otro nutre sus principios y tradiciones y así mismo cada uno gana un poco más de humanidad al sentir que no es uno, sino que se está potencializando en todos.

De allí la necesidad de reevaluar las practicas pedagógicas verticales, en tanto que estos modelos no facilitan el ejercicio crítico, significativo, vivencial y democrático al interior de los procesos de enseñanza aprendizaje. Por el contrario, mantienen al educando al margen del temor, el mismo con el que fue formado y uniformado el alter-autoritario (llámese, profesor, maestro, mandatario) quien impone y reproduce la tabla de valores que le fue impuesta en algún momento de su formación y bajo unos intereses ajenos a los que tiene su formando. Promover los principios que sustentan la educación en equidad y género es uno de los pilares de esta propuesta curricular.

El currículo desde la perspectiva de las ECF debe llevar a los estudiantes y las estudiantes a generar un pensamiento crítico y autocrítico. Pero para que genere impacto en los estudiantes, es indispensable tener en cuenta, las siguientes recomendaciones para analizar y reestructurar el currículo.

El currículo tradicional. En primera instancia se debe realizar una introducción, donde se resalte la importancia del conocimiento visto siempre como un peldaño, en el proceso de construcción 


\section{Epistemologías Críticas Feministas}

del saber. Seguidamente, presentar las temáticas, de la manera tradicional; esto es, como se han seleccionado, organizado y distribuido hasta el momento. Con el fin de analizar, que impacto han generado en la sociedad, y cómo justifican que la ciencia promueva situaciones tales como: las relaciones sociales de poder, los estereotipos de género, la distribución del campo laboral y científico. Con el fin de reflexionar más adelante sobre las debilidades, las polémicas y las denuncias que las críticas feministas han extraído del saber científico.

Equidad en el currículo. El currículo para que sea equitativo debe tener en cuenta el hecho de que ya no estará dirigido al hombre como representante de la humanidad, sino a los hombres y las mujeres, quienes aunque individuos de la humanidad universal, habitan en un contexto específico, con problemas, que deben ser solucionados desde el contexto en el que se encuentran, para concientizar sobre la importancia que tiene evitar constantemente la referencia a universalismos y generalizaciones que son comunes en el currículo tradicional.

Seguidamente mostrar las debilidades, las polémicas y las denuncias que las críticas feministas han extraído del saber científico. Hay que incentivar en los educandos la reflexión sobre el carácter paradigmático de las ciencias tal cómo exponía Kuhn, y la importancia de los errores para que exista movilidad en el saber, tal y como exponía Feyerabend.

Mutabilidad de las teorías. Los estudiantes y las estudiantes deben comprender que no existen conocimientos fijos o verdades inmutables, por el contrario, que siempre deben exponer sus conocimientos al examen constante sin importar la fuente o el origen de donde provengan. Que el conocimiento siempre ha sido construido para beneficiar lo masculino y en consecuencia, solo existe una perspectiva parcial del saber (el de los hombres), hace falta complementarlo con la perspectiva de las mujeres, pero fundamentalmente debe quedar claro en los objetivos del currículo, que sin importar de donde provenga el conocimiento, como lo enunciaba Harding, siempre existirá la posibilidad de replantearlo y retroalimentar las ciencias a través de nuevas reflexiones y descubrimientos.

La deconstrucción de la historia. Es fundamental deconstruir el sentido universalista que se le ha asignado a la historia. Hay que reflejar en cada una de las temáticas que se proyecten, cómo la 


\section{Epistemologías Críticas Feministas}

sociedad ha hecho de los acontecimientos en los que figuran los hombres, los únicos válidos para recordar en la historia, razón por la cual, es importante mostrar; que las mujeres siempre han estado presentes y que en muchas ocasiones su papel ha sido protagónico más que de auxiliares o asistentes de los hombres. También se debe ampliar lo que se entiende por grandes acontecimientos y revalorar los ámbitos relacionados con lo femenino.

Referencias bibliográficas de mujeres. Los referentes bibliográficos en el currículo deben ser variados respecto a sus creadores (autores y autoras de diferentes etnias, nacionalidades, religiones entre otras), con el fin de motivar reflexiones en las que se asuma una postura específica frente a los descubrimientos científicos, el arte, la cultura, la religión, la historia; donde se tenga acceso a la confrontación y a la elección, donde se motive al estudiante a nunca estar satisfecho con lo que conoce sino que siempre debe estar a la vanguardia de los nuevos avances y descubrimientos, sin desconocer que cada reflexión, teoría y creación artística o científica ha representado un peldaño más en la construcción del conocimiento.

Flexibilidad del currículo. El currículo debe convertirse en un espacio de conflicto y debate, donde no solo estén involucrados los docentes, también deben estar inmersos los estudiantes y los padres de familia. El currículo debe reflejar la realidad que los estudiantes viven, para que al problematizar cada una de las disciplinas también se pueda problematizar el contexto en el que se encuentran y la responsabilidad social de la investigación científica. Debe estar presto a cambios constantes en el que pueda incorporar y descartar ideas, acontecimientos y problemáticas que las circunstancias de la historia van presentando en el día a día.

Además, este modelo de currículo debe reflejar que todos los seres humanos nacemos libres y con grandes diferencias el uno del otro, que es válido invocar diferencias y asumir la individualidad sin temor, pero que es inaceptable erigir prejuicios o estereotipos en nombre de la moral, las costumbres o la sociedad. Los seres humanos tenemos el derecho a ser y a existir, la obligación de reconocer al otro u otra como iguales, iguales ante la ley, pero diferentes (y libres) en su individualidad. Aceptar que somos diferentes, es fundamental, para vivir la justicia, la solidaridad y la convivencia armónica 


\section{Epistemologías Críticas Feministas}

\section{El estudiante y la perspectiva de género}

Teniendo en cuenta los planteamientos de las ECF, proponemos que en el ámbito educativo la enseñanza de las ciencias, el currículo y la formación docente deben centrarse en mostrar que el saber científico se produce en contextos específicos, que está ligado a la realidad social y humana del investigador. En la escuela, debe problematizarse la categoría de universalidad en las ciencias, esto permitirá involucrar a los estudiantes y las estudiantes en el conocimiento y reconocerse en él, ya que se mostrarán los diferentes contextos en los que se producen las ciencias.

El impacto que debe generar el cambio de perspectiva de los docentes en los procesos de enseñanza-aprendizaje para la equidad y la transformación del currículo, encuentra como sujeto depositario al educando. El impacto y la resistencia inicial son predecibles en un ambiente machista donde incluso la mayoría de niñas defienden el perfil de lo que significa en esta sociedad ser hombre o ser mujer, perfil o «género individual» que ha sido inculcado por los sistemas androcéntricos imperantes.

Las relaciones de poder que se han impuesto, fluyen en la sociedad como una distribución justa que hay que aceptar y reproducir. Sin embargo, la crítica feminista decolonial a través de la Pedagogía Roja ${ }^{15}$ ha contribuido en el intento de esta deconstrucción, «principalmente aquellos relacionados con los modos en que la pedagogía feminista, como conocimiento situado, potencialmente reproduce relaciones de poder y dominación históricamente configurados y transversales a nuestra constitución como sujetos co-constituídos por la raza y el género» (Pérez, 2010, p. 25). «La pedagogía feminista cuestiona los sistemas universalizantes de conocimiento y de verdad anclados (materialmente) a sistemas de dominación capitalista en donde se encuentra la ciencia, y cómo sus seguidores, promulgan por la transformación social de éstos a través de concientización y diálogo (Weiler, 1991; Villenas 2006; como se citó en Pérez, 2010, p. 252253).

\footnotetext{
${ }^{15}$ Proyecto que cuestiona tanto la democracia como la soberanía indígena. En este contexto, la soberanía se define, en líneas generales, como «el derecho del pueblo a reconstruir sus reivindicaciones en cuanto a su existencia y a su capacidad de mostrar sus dones ante el mundo (McLaren, 2008, p. 457).
} 
Utilizar las ECF como horizonte implica que en la escuela se trabaje una transformación en el género individual, es decir en la autopercepción que los estudiantes y las estudiantes tienen de sí mismos, en relación con la sociedad en la que habitan. El estudiante debe identificar que el rol que desempeña en el contexto en el que se encuentra, le permite tener una idea más o menos clara de quién es, de cómo relacionarse sin ver comprometida su identidad. Puede suceder, que después de éste tipo de reflexiones, comprenda que su realidad es única y que la puede afectar con sus ideas y acciones de manera positiva y negativa.

Esta autopercepción puede mejorarse a través del fortalecimiento del liderazgo. En as prácticas educativas existen mujeres que postulan su liderazgo, pero suceden dos situaciones dentro del aula: La primera es la falta de respaldo que tienen de parte de sus congéneres. Hay algunas circunstancias de tipo moral que determinan la participación de las mujeres en actividades políticas y sociales como lo son el orgullo, la envidia, la indiferencia, la falta de credibilidad, entre otros valores que se relacionan con los expuestos por Harding: las conductas suaves, delicadas, emocionales, no competitivas y asistenciales. Y la segunda situación radica en la falta de confianza que tienen de sí mismas: el temor de carecer de liderazgo, autoridad, e ímpetu para llevar a cabo responsabilidades sociales, son algunos de los condicionamientos que la conciencia de una sociedad machista les ha infundido. Estas son las razones que algunos docentes encuentran de parte de sus estudiantes, cuando se realizan actividades democráticas o de participación social al interior de las aulas de clase en las instituciones educativas.

Otro punto importante para favorecer un modelo de enseñanza de las ciencias que promueva la equidad de género, es demostrar que los conceptos, teorías y problemas de las ciencias han cambiado en el tiempo. El pensamiento humano ha creado formas de utilizar las ciencias, la cultura y la educación, para conservar el poder. Hay que demostrar que la construcción del conocimiento ha consistido en un proceso diacrónico, que ha tenido como puntos de referencia algunos acontecimientos sincrónicos. Es decir, que la ciencia ha venido construyéndose en el día a día de la historia, a partir de las necesidades de la sociedad y que cada descubrimiento se ha acentuado por un periodo determinado de tiempo, convirtiéndose en paradigma con el transcurrir del tiempo, reemplazando uno por otro y así sucesivamente. 


\section{Epistemologías Críticas Feministas}

En el reconocimiento mismo del proceso histórico-social de la construcción de las ciencias, se pretende que el estudiante adquiera una actitud crítica frente a todos los conocimientos, que tenga la capacidad de reconocer en los textos y contextos una relación significativa con la realidad en la que vive. El educando debe tener la capacidad de reconocer que sólo puede interpretar de la realidad simbólica, solo una parte de lo que quiere transmitir, porque la intencionalidad original siempre será incierta. Reconocer que siempre existirá en el conocimiento intereses e ideologías implícitas que pretenden imponerse ante el lector. Identificar, que en suma, el saber es una construcción social e histórica hecha por personas con múltiples intereses y deseos que estarán presentes en el conocimiento de manera intrínseca.

Al reconocer que el saber científico, es una construcción humana que surgió como consecuencia de un periodo específico, en algún lugar del planeta, se tendrá mayor cautela en la lectura que se realice, sobre cualquier disciplina que se estudie. De esta forma, el educando no va a desconocer que las ciencias son una construcción de la sociedad y que el hecho de ser construcciones del pensamiento humano, son susceptibles al cambio. Un caso de las deficiencias del saber científico es el sesgo androcéntrico, que ha puesto en entredicho las categorías de neutralidad y pureza.

En el reconocimiento de las debilidades desde las ciencias mismas se logra sensibilizar y motivar al educando para que continúe investigando en torno a la creación, estructuración y distribución de las ciencias, esta manera de inducir al estudiante se le denominará Conciencia crítica. Carreño (2010), concibe la conciencia crítica como la superación progresiva de la conciencia intransitiva, la conciencia crítica se logra con una educación dialogal y activa, caracterizada según Freire (2002)

(...) por la profundidad en la interpretación de los problemas. Por la sustitución de explicaciones mágicas por principios causales, por tratar de comprobar los descubrimientos y estar dispuesto siempre a las revisiones [...] Por la práctica del diálogo y no de la polémica. Por la receptividad de lo nuevo, no solo por nuevo, y por la no-negación de lo viejo solo por viejo, sino por la aceptación de ambos, en cuanto a su validez (p. 55). 
En un proceso de articulación social y político de lo antiguo con lo nuevo, como dice Freire de transición hacia la democracia. Es una responsabilidad social y política que exige de la educación, la articulación de las letras y la realidad a través del diálogo.

La finalidad es hacer énfasis, en las contradicciones y paradojas que trae consigo pensar una práctica pedagógica crítica, que resista las dinámicas de opresión, la invisibilización de las subjetividades y sus experiencias biográficas, así como la estandarización epistemológica y didáctica. De tal forma, que los educandos desde lo popular o cotidiano reconozcan la necesidad de adquirir una postura crítica frente a la ciencia y la filosofía, que les facilite repensar la realidad desde perspectivas diversas que ofrezcan complicaciones y posibles soluciones desde posturas multidimensionales. Pensadores como Freire (1970) Pérez (2010), Carreño (2010) y Huergo (2001), coinciden en que

una de las grandes - sino la mayor- tragedia del hombre moderno es que hoy, dominado por la fuerza de los mitos y dirigido por la publicidad organizada, ideológica o no, renuncia cada vez más, sin saberlo, a su capacidad de decidir. Está siendo expulsado de la órbita de las decisiones» (Freire, 2002, p. 33).

Sin embargo, «la alienación y la deshumanización son situaciones circunstanciales y, por lo tanto, superables. El medio para lograr esa superación, es una educación dialogal y activa que supone un trabajo educativo crítico» (Carreño, 2010, p. 204-205), lo cual implica la necesidad de transformar los métodos, teorías y técnicas tradicionales de enseñanza, a partir del diálogo y la conciencia crítica como superación de la conciencia intransitiva ${ }^{16}$, claro está, si existen pretensiones serias frente a una posible transformación desde las aulas de clase y por ende, de las instituciones educativas frente a la conciencia social.

\footnotetext{
${ }^{16} \mathrm{La}$ conciencia intransitiva genera una sociedad sin diálogo, sin comunicación que conduce a lo que Freire denomina cultura del silencio. Esta se corresponde con las sociedades cerradas que son aquéllas "a las cuales se les niega el diálogo-comunicación y en su lugar se les ofrecen «comunicados». [Estas sociedades], se hacen preponderantemente «mudas». El mutismo no es propiamente inexistencia de respuesta. Es una respuesta a la que le falta un tenor marcadamente crítico. Tomado de: Freire, P. (1978) Pedagogía del oprimido. Madrid: Siglo XXI, p. 63.
} 


\section{Epistemologías Críticas Feministas}

En síntesis, según los autores citados, se deben concentrar los esfuerzos en la identificación de las problemáticas inmediatas que aquejan a niños, niñas y adolescentes, hombres y mujeres que interactúan en el medio en el cual se desenvuelve su quehacer cotidiano. Siguiendo a Tania Pérez

El principal llamado de atención será a considerar cómo el potencial liberador de la educación puede verse dinamizado y limitado por los modos en que se ejerce la autoridad y se reconoce, o no, el poder epistemológico de la experiencia (biográfica, colectiva, histórica) y de las diferencias en el plano de la cotidianidad del ejercicio educativo (Pérez, 2010, p. 253).

De esta forma, se puede hacer un llamado de atención a cuestionar los supuestos en torno al género, la etnia, la clase social entre otros. Teniendo como referente la reflexión pedagógica feminista sobre la autoridad, la experiencia y la diferencia.

\section{A modo de conclusión}

Se ha realizado una breve pero concisa presentación de tres perspectivas epistemológicas: La epistemología tradicional, la epistemología crítica y las epistemologías críticas feministas.

A partir de estas tres perspectivas epistemológicas se presentaron tres capítulos, en los que se han contextualizado 1) algunas definiciones y posturas que se han elaborado en torno a una posible conceptualización de lo que es la epistemología, 2) las limitaciones que las ECF han encontrado en el quehacer científico tradicional y algunas propuestas para contrarrestar el impacto que estas limitaciones ejercen en contra de la participación social de las mujeres y 3) la propuesta para incorporar en la escuela las estrategias que permitan, desde la enseñanza Primaria y Secundaria, formar e inducir a los educandos a pensar y vivir en el colectivo sin perder su individualidad, teniendo como base de sus reflexiones, críticas e interacciones, la perspectiva de la equidad de género.

La finalidad de esta contextualización epistemológica también consistió en definir el recorrido histórico que las ciencias y la filosofía de las ciencias han realizado para entender por qué el 
saber científico ha optado por negar la estrecha relación que existe entre la investigación, la historia y la sociedad. De igual manera, identificar por qué la ciencia tradicional ha adoptado como parte de sus teorías, marcos teóricos y problemas, un sesgo androcéntrico que ha llevado a la estructuración de estereotipos de género (El simbolismo de género, la estructuración social de género y el género individual), que se han venido reproduciendo y naturalizando en contra de la participación equitativa de la humanidad, otorgándole la preponderancia histórica y científica a la figura masculina De esta forma se ha limitado la participación de las mujeres en el quehacer científico y en todas las actividades e instituciones sociales.

Así, hemos contextualizado el problema que se planteó para la realización de este trabajo. La finalidad ha consistido en identificar cómo se podían incorporar las propuestas de las ECF en la escuela y si era posible articularlas en la educación. La respuesta a la que hemos llegado es que sí es posible incluirlas en la educación, pero para ello, es necesario introducir tres principios fundamentalmente, 1) El saber científico es el resultado de un proceso diacrónico, 2) El saber científico es tan solo una forma de hacer ciencia y 3) El sesgo androcéntrico ha estado implícito en el saber científico.

Las propuestas que hemos realizado a partir de la identificación de las limitaciones de las ciencias son:

1) El cambio de perspectiva sobre el género que tienen los docentes, a través de cursos, seminarios-talleres, ya que son los profesores quienes deben, a través de sus clases, inducir a los estudiantes a reflexionar de manera crítica sobre las ciencias y los problemas que denuncian las ECF que ellas poseen, para que desde sus reflexiones (los estudiantes y las estudiantes), descubran los estereotipos que se han naturalizado, el impacto de estos en la vida de las mujeres, las oportunidades que tienen independientemente de su condición social, cultural o sexual, de participar en los procesos disciplinares, campos laborales que dentro de sus aptitudes quieran conocer y desempeñar profesionalmente,

2) La formulación de un currículo que amplíe en las estudiantes la perspectiva del único mundo que se ha mostrado (el mundo masculinizado), que evidencie la existencia de dos perspectivas 


\section{Epistemologías Críticas Feministas}

que corresponden a seres humanos diferentes con oportunidades frente al saber científico y el campo laboral que son indistintas al género, clase social, etnia, cultura, y que garantice en las estudiantes, el reconocimiento de la posición de las mujeres como sujetos de conocimiento.

3) La identificación del género como una construcción social será fundamental para que los estudiantes empiecen a realizar interacciones sociales equitativas. El esclarecimiento de la diferencia entre sexo (como constitución fisiológica) y el género (como construcción social) va a evitar que los estudiantes continúen reforzando los estereotipos y dicotomías que tienen que ver con la relación de lo femenino como sinónimos de debilidad, inseguridad, inferioridad, irracionalidad. Desde esta perspectiva el estudiante estará en la capacidad de reconocer que la constitución fisiológica del cuerpo no determina el género del individuo, pues en un cuerpo de hombre, puede habitar el género femenino y viceversa. La dignidad humana en el modelo educativo de equidad de género prima por sobre cualquier tradición histórica, religiosa y cultural.

\section{Referencias Bibliográficas}

Amorós, C. y De Miguel, A. (2005). Teoría feminista. De la Ilustración a la globalización. Madrid: Ediciones Minerva.

Angulo, L. N., León, A. R. (2005). Perspectiva crítica de Paulo Freire y su contribución a la teoría del currículo. Venezuela: Educere.

American Psychological Association (APA). Normas MFL. (2015). Bogotá. Universidad Santo Tomás.

Ballarín, P. (2006). La educación «propia del sexo» En Género y Currículo: Aportaciones del género al estudio y práctica del currículo. Madrid: Akal. 


\section{Epistemologías Críticas Feministas}

Barberá, E. y otros. (2004). Rompiendo el techo de cristal: los beneficios de La diversidad de género en los equipos de Dirección. Programa Sectorial de Estudios de las Mujeres. Valencia: Universidad de Valencia.

Beauvoir, S. (2005). El segundo Sexo. Madrid: Ediciones Cátedra.

Blanco, R. (1994). Las relaciones entre ciencia y sociedad: hacia una sociología histórica del conocimiento científico. Madrid: Plan Nacional Político y Social.

Boladeras, M. (1996). Comunicación, ética y política. Habermas y sus escritos. Madrid: Tecnos.

Boscán, A. (2011). Perspectivas epistemológicas y metodológicas de la investigación feminista. Venezuela: Universidad del Zulia.

Butler, J. (2001). Fundamentos contingentes: el feminismo y la cuestión del posmodernismo. Buenos Aires: Centro de Documentación sobre la Mujer.

Caballero, M. (2000). Currículo y Género. Paraguay: Priome.

Carreño, M. (2010). Teoría y práctica de una educación liberadora: el pensamiento pedagógico de Paulo Freire. Madrid: Secretariado de Publicaciones Universidad de Sevilla.

Colás, P. (2003). Investigación educativa y crítica feminista. Ágora digital. N. 6. pp. 11-22.

Cruz, M, Reyes, M. J., Cornejo, M. (2012). Conocimiento situado y el problema de la subjetividad del investigador/a. Chile: Cinta moebio.

David, M. (1994). «Introducción crítica: género y educación». En ACKER, S. Género y educación. Reflexiones sociológicas sobre mujeres, enseñanza y feminismo. Madrid: Narcea. 


\section{Epistemologías Críticas Feministas}

Del Moral, E. (01 de Dic., de 2012). En transición. La epistemología y filosofía feminista de la ciencia ante los retos de un contexto de crisis multidimensional. E-cadernos ces (Online). http//eces.revues.org/1521;DOI:10:4000/eces.1521.

Díaz, S. (2005). La Ilustración en la Nueva Granada: Su Influencia en la Educación en el Movimiento de la Emancipación, el caso de Mutis. Boletín de Historia y Antigüedades, Vol. XCII, No. 828 (2005): 120.

Díez, J. A., Moulines, C.U. (1999). Fundamentos de filosofía de la Ciencia. Barcelona: Ariel.

Dorlin, E. (2008). Sexo, género y sexualidades: Introducción a la teoría feminista. Buenos Aires: Nueva Visión.

Evans, R. (1980). Las feministas. Los movimientos de emancipación de la mujer en Europa, América y Australia. (1840-1920). Madrid: Siglo XXI.

Fox, Keller Evelyn. (1991). Reflexiones sobre género y ciencia. Valencia: Alfons el Magnanim.

Foz y Foz P. (1997). Mujer y Educación en Colombia, siglo XVI-XIX. Aportaciones del colegio de la enseñanza 1783-1900. (Bogotá: Academia Colombiana de Historia, 1997), p. 265.

Freire, P. (2002). La educación como práctica de la libertad. Madrid: Siglo XXI.

Gallegos, C. y Rosales, G. (2012). Epistemología Crítica. Bogotá: Itinerario Educativo USB.

García, C. (2008). Reconfiguración como sujetos de comunicación: implicaciones para los ambientes virtuales con fines educativos. Revista de universidad y sociedad del conocimiento.

García, Schlegel María (1995). Las Mujeres en la Ilustración, las Voces de la Madre Petronila. En Las mujeres en la Historia de Colombia, Bogotá: Norma. Tomo I. 


\section{Epistemologías Críticas Feministas}

Gargallo, F. (Año II, Nro. 2, marzo 2008). Para pensar cómo deconstruir el feminismo hegemónico en nuestra américa. A manera de provocación reflexión. En. Encuentros latinoamericanos. Montevideo: ceil.

Godineau, D, (1995). “La Mujer”. En El Hombre de La Ilustración (ed.) Michel Vovelle. Madrid: Alianza.

González, D. (Enero-Junio de 2015). La educación de las mujeres en Colombia a finales del siglo XIX: Santander y el proyecto de educativo de la regeneración. Santander: CIESAS. Vol. 17 N. 24. Pp. 243 -258.

González, Lobo y otros, (1999). Revista mexicana de investigación educativa. Vol. 5, N. 8.

González, M., Pérez, E. (2002). Ciencia Tecnología y Género. Revista Iberoamericana de Ciencia Tecnología Sociedad e Información, (2) enero-abril.

Haraway, D.J. (1995). Ciencia, ciborgs y mujeres. La reinvención de la naturaleza. Madrid: cátedra.

Harding, S. (1996). Ciencia y Feminismo. Madrid: Morata.

Harding, S. (2004). The feminist stanpoint reader. New York: Routledge.

Huergo, J. (2001). "La popularización de la ciencia y la tecnología: interpelaciones desde la comunicación", presentado en el Seminario Latinoamericano Estrategias para la Formación de Popularizadores en Ciencia y Tecnología. Red-POP-Cono Sur. Recuperado de: http://www.redpop.org/publicaciones/lapopularizacion.html.

Jaramillo, L. (2003). ¿Qué es la epistemología? Santiago de Chile: Cinta de Moebio. 


\section{Epistemologías Críticas Feministas}

McLaren, P y Kincheloe, J. L. (2008). Pedagogía crítica: De que hablamos, donde estamos. Barcelona: GRAÓ, de IRIF, S.L.

Maffia, D. (2007). Epistemología feminista: La subversión semiótica de las mujeres en la ciencia. Buenos Aires: Universidad de Buenos Aires.

Mardones, J. (2001). Filosofía de las ciencias humanas y sociales. España Anthrópos.

Margot, J. P. (1977). Reflexiones en torno a la epistemología histórica. Ideas y Valores. [S.1.], v. 27, n. 50, p. 13-34, feb. 1977. Disponible en: <http://www.revistas.unal.edu.co/index.php/idval/article/view/21697/22683>. Fecha de acceso: 03 nov. 2016.

Martínez, M. (2003). Epistemología Feminista y posmodernidad. Chile: Cinta de Moebio 16.

Martínez M. (5 de septiembre de 2012). Revista Latinoamericana. El proceso de nuestro conocer postula un nuevo paradigma epistémico. Santiago: CISPO, Polis.

Montero, J. (2006). Feminismo un movimiento crítico. Madrid: Asamblea feminista de Madrid.

Morin. E. (1982). Ciencia con Conciencia. México: Mundo Real.

Pérez, A.I. (1998). La cultura escolar en la sociedad neoliberal. Madrid: Morata.

Pérez, B. T. (2010). Aportes feministas a la Educación popular: entradas para repensar pedagógicamente la popularización de la ciencia y la tecnología. Bogotá: Universidad Pedagógica Nacional.

Piaget, J. (1979). Tratado de lógica y conocimiento científico (1). Naturaleza y métodos de la epistemología. Buenos Aires: Paidós. 


\section{Epistemologías Críticas Feministas}

Posada, K. (2010). Igualdad, epistmeología y género: desde un horizonte ético-político, Madrid: Universidad complutense de Madrid.

Ramírez, M. (2010). La primera mujer entra a la universidad En La mujer en la historia de la educación superior. Bogotá: Universia.

Rodríguez, C. (2002). De alumna a maestra: un estudio sobre socialización docente y prácticas de Enseñanza. Granada: Universidad de Granada.

Rodríguez, C. (2006). Género y Currículo: Aportaciones del género al estudio y práctica del currículo. Madrid: Akal.

Salazar, R. R. (1993). Introducción a la epistemología. Bogotá: Unisur.

Santos, B. (2000). Crítica de la razón indolente: Contra el desperdicio de la experiencia. Sao Paulo: Descleé de Brower. Vol. I.

Simón, M. (2011). La igualdad también se aprende: cuestión de coeducación. Madrid: Narcea Ediciones.

Thuillier, P. (1990). El saber Ventrilocuo. México: FCE.

Villarmea, R. (1999). Conocimientos situados y estrategias feministas. Madrid: Universidad de Madrid.

Williams, J. (1999). Igualdad sin discriminación, en Género y Derecho, editado por Alda Facio y Lorena Fríes, Santiago de Chile, Ediciones LOM, pp. 75-97. Traducido por Paquita Cruz. 